\title{
Aspirin blocks growth of breast tumor cells and tumor-initiating cells and induces reprogramming factors of mesenchymal to epithelial transition
}

\author{
Gargi Maity ${ }^{1,2}$, Archana De ${ }^{1}$, Amlan Das ${ }^{1,2}$, Snigdha Banerjee ${ }^{1,3}$, Sandipto Sarkar ${ }^{1,4}$ and Sushanta K Banerjee $e^{1,2,3,4}$
}

Acetylsalicylic acid (ASA), also known as aspirin, a classic, nonsteroidal, anti-inflammatory drug (NSAID), is widely used to relieve minor aches and pains and to reduce fever. Epidemiological studies and other experimental studies suggest that ASA use reduces the risk of different cancers including breast cancer $(B C)$ and may be used as a chemopreventive agent against $B C$ and other cancers. These studies have raised the tempting possibility that ASA could serve as a preventive medicine for BC. However, lack of in-depth knowledge of the mechanism of action of ASA reshapes the debate of risk and benefit of using ASA in prevention of BC. Our studies, using in vitro and in vivo tumor xenograft models, show a strong beneficial effect of ASA in the prevention of breast carcinogenesis. We find that ASA not only prevents breast tumor cell growth in vitro and tumor growth in nude mice xenograft model through the induction of apoptosis, but also significantly reduces the self-renewal capacity and growth of breast tumor-initiating cells (BTICs)/breast cancer stem cells (BCSCs) and delays the formation of a palpable tumor. Moreover, ASA regulates other pathophysiological events in breast carcinogenesis, such as reprogramming the mesenchymal to epithelial transition (MET) and delaying in vitro migration in BC cells. The tumor growth-inhibitory and reprogramming roles of ASA could be mediated through inhibition of TGF- $\beta$ / SMAD4 signaling pathway that is associated with growth, motility, invasion, and metastasis in advanced BCs. Collectively, ASA has a therapeutic or preventive potential by attacking possible target such as TGF- $\beta$ in breast carcinogenesis.

Laboratory Investigation (2015) 95, 702-717; doi:10.1038/labinvest.2015.49; published online 13 April 2015

Breast cancer $(\mathrm{BC})$ is one of the most common malignancies among women; it attacks 1 in 8 women $(\sim 12 \%)$, affecting nearly every family worldwide. ${ }^{1,2}$ Although increased early diagnosis and new therapeutic regimens have significantly improved BC survival, the therapeutic options for BC are still limited and have transient efficacy owing to primary or acquired resistance. ${ }^{3,4}$ Because of partial remission of $\mathrm{BC}$, minimal residual disease (tumor mass dormancy, tumor cell dormancy) may present and persist for years to decades. ${ }^{5,6}$ The residual $\mathrm{BC}$ cells often are considered 'breast tumorinitiating cells (BTICs)' or 'breast cancer stem cells (BCSCs)' as after conventional therapy these cells display both mesenchymal and tumor-initiating features ${ }^{7}$ and could be resistant to antichemotherapy and exhibit high metastatic potential. ${ }^{7,8}$ In a favorable scenario, residual BC cells enter into a fast-dividing mode that brings on disease relapse.,
Given the significant pathological implication of residual BC cells, there is an urgent need to develop a new comprehensive and prolonged treatment strategy with no or less cytotoxic impact to eliminate or delay the growth of BTICs/BCSCs for preventing disease relapse and enhance long-term survival of BC patients.

Aspirin (also known as acetylsalicylic acid (ASA)) and other nonsteroidal, anti-inflammatory drugs (NSAIDs) are widely used to manage pain, arthritis, and cardiovascular diseases. Epidemiological evidence, randomized control trials (RCTs), and experimental data indicate the beneficial effect of ASA in prevention, progression, and metastatic growth of various cancers including colon, GI cancers, prostate cancer, and $\mathrm{BC}$ through complex COX-2-dependent or -independent complex pathways. It is clear from various studies that the beneficial effect of ASA is dose and time dependent.

Cancer Research Unit, VA Medical Center, Kansas City, MO, USA; ${ }^{2}$ Department of Pathology, University of Kansas Medical Center, Kansas City, KS, USA; ${ }^{3}$ Division of Hematology and Oncology, Department of Internal Medicine, University of Kansas Medical Center, Kansas City, KS, USA and ${ }^{4}$ Department of Anatomy and Cell Biology, University of Kansas Medical Center, Kansas City, KS, USA

Correspondence: Professor S Banerjee, PhD or Professor SK Banerjee, PhD, Cancer Research Unit, Research Division 151, VA Medical Center and University of Kansas Medical Center, 4801 Linwood Boulevard, Kansas City, MO 64128, USA.

E-mail: sbanerjee@kumc.edu or sbanerjee2@kumc.edu

Received 5 November 2014; revised 10 February 2015; accepted 16 February 2015 
For example, a preventive benefit can be accumulated after $\geq 5$ years of using a low daily dose of ASA ( $\leq 100 \mathrm{mg} /$ day), whereas a higher-risk individual may need a standard dose (300-350/day) or higher $(>600 \mathrm{mg} /$ day $)$ of ASA. ${ }^{9-12}$ Although little or no effect was mentioned in other major cancer sites including pancreatic, endometrial, and hematopoietic cancers, ${ }^{12-14}$ recent studies demonstrated that the use of ASA may reduce the risk of the development of pancreatic cancer, ${ }^{15}$ and a low dose of nitric oxide-releasing ASA inhibits pancreatic carcinogenesis in mouse models by modulating multiple molecular targets. In BC, compared with other cancers, fewer studies have been documented, and the results of these few studies found less beneficial impact of ASA as compared with colon cancer or GI-related cancers. ${ }^{12,14,16}$ However, recent studies have found that premenopausal women who took two or more aspirin each week in the years after a diagnosis of early-stage $\mathrm{BC}$ had a better prognosis than women who did not take ASA, indicating that ASA use was associated with a decreased risk of distant recurrence and BC death. ${ }^{17}$ Thus, we hypothesize that ASA therapy may alter the pathobiological and molecular signatures in $\mathrm{BC}$ cells that are associated with drug resistance, disease relapse, or disease progression. To establish the hypothesis, here we provide detailed characterization of the activity of ASA in different BC cells and a mouse xenograft model.

\section{MATERIALS AND METHODS}

\section{Regents, Chemicals, and Antibodies}

Aspirin (ASA) was purchased from Sigma Aldrich (St Louise, MO, USA). A $1 \mathrm{M}$ stock solution of ASA was prepared in DMSO and all dosage forms were freshly prepared before each experiment. Dulbecco's modified Eagle's medium (DMEM), penicillin-streptomycin, and trypsin-EDTA solution were purchased from Sigma (St Louis, MO, USA). All other chemicals were obtained from either Sigma or Fisher Scientific (Fisher Scientific, Houston, TX, USA). Fetal bovine serum (FBS) was obtained from HyClone (Logan, UT, USA). Rabbit polyclonal antibodies, such as Oct-4 (2750), CD44 (3578), Caspase-3 (9665), Snail (3879), TGF- $\beta 1$ (3711), and TGF $\beta$ IIR were purchased from Cell Signaling Technologies (Beverly, MA, USA), COX-2 (RB-9072) and Keratin-19 (RB-9021) were purchased from Thermo Scientific (Fremont, CA, USA), PCNA (sc-7907), Bax (sc-526), TWIST (sc-15393), and SMAD4 (sc-7966) were purchased from Santa Cruz Biotechnologies (Santa Cruz, CA, USA), and Notch-1 (ab27526) was purchased from Abcam (Cambridge, MA, USA). Monoclonal mouse antibodies such as Bcl-2 (sc-7382) and ADH (sc-133207) were purchased from Santa Cruz Biotechnologies, Vimentin (MS-129) was purchased from Thermo Scientific, E-cadherin (610404) from BD Biosciences (San Jose, CA, USA), and GAPDH from Applied Biosystems (Foster City, CA, USA). The dilution of the antibody was made as per manufacture's recommendations, $\sim 1: 500$ to $1: 1000$.

\section{Cell Lines and Culture Conditions}

MCF-7 (luminal, ER ${ }^{+}$) and MDA-MB-231 (mesenchymaltype/basal-type triple-negative BC (TNBC)) BC cell lines were purchased from American Type Culture Collection (ATCC, Manassas, VA, USA). The cell lines were cultured in DMEM supplemented with $10 \% \mathrm{FBS}, 2 \mathrm{mM}$ glutamine, 100 units $/ \mathrm{ml}$ penicillin, and $100 \mathrm{units} / \mathrm{ml}$ streptomycin (Sigma) at $37^{\circ} \mathrm{C}$ in an incubator in the presence of $5 \% \mathrm{CO}_{2}$. For the experiment, cells were used between four and six passages.

\section{Cell Viability Assay}

Cells were plated in quadruplicates in 96-well plates and incubated at $37^{\circ} \mathrm{C}$ with $5 \% \mathrm{CO}_{2}$ overnight for attachment and growth. Approximately $60 \%$ confluent cells were treated with different doses of ASA dissolved in DMSO (SigmaAldrich) or DMSO alone (control) for $72 \mathrm{~h}$. Cellular viability was measured using crystal violet-based cell viability and cytotoxicity assay (CytoSelect ${ }^{\mathrm{TM}}$ Cell Viability and Cytotoxicity Assay kits, Cell Biolabs, San Diego, CA, USA) as described earlier by Kambhampati et al ${ }^{18}$ and Trypan blue exclusion assay (Life Technologies, Grand Island, NY, USA).

\section{Cell Proliferation Assay}

BC cells (MCF-7 and MDA-MB-231) were seeded at a density of $1 \times 10^{4}$ cells/well of 96-well plates containing DMEM with $10 \%$ FBS. After attachments, cells were treated with different doses of ASA or DMSO for different times. Cell proliferation was determined by BrdU-ELISAs (colorimetric) according to the manufacturer's instructions (Roche Diagnostics, Indianapolis, IN, USA). Briefly, 3 hours before the indicated time of treatment, cells were treated with BrdU solution $(10 \mu \mathrm{l} /$ well). Following BrdU treatment, cells were incubated with FixDenat solution for $30 \mathrm{~min}$ and then incubated with BrdU POD for $90 \mathrm{~min}$ at room temperature. Cells were rinsed thoroughly with washing solution and incubated with substrate solution at room temperature and processed for photometric detection.

\section{Apoptosis Assay}

Apoptotic cell death in DMSO alone (untreated) and ASA-treated BC cells was determined using cell death detection ELISA kits (Roche Diagnostic). Briefly, untreated and ASA-treated cells were harvested and lysed with lysis buffer. The cytoplasmic supernatant was collected, and the total protein was estimated. A total of $20 \mu \mathrm{l}$ of cell lysate containing $10 \mu \mathrm{g}$ of protein was added in the streptavidincoated microplate and allowed to react with $80 \mu \mathrm{l}$ of buffer mixture containing anti-histone-biotin and anti-DNA-peroxidase for $2 \mathrm{~h}$ with continuous shaking. Microplates were washed with incubation buffer. The ABTS (2,2\$-azino-di-(3ethylbenzthiazoline-6-sulfonic acid)) chromogen substrate was added to get a color reaction that was measured in the ELISA reader at $405 \mathrm{~nm}$. 


\section{Western Blot Analysis}

The Western blot analyses were conducted as previously described. ${ }^{19-21}$ Briefly, $50 \mu \mathrm{g}$ total protein was separated by SDS-PAGE and transferred to nitrocellulose membrane (Trans-blot transfer medium, Bio-Rad). The membranes were probed with primary antibodies for a specified period of time as per the manufacturer's instructions. Blots were washed in TBS-T and incubated with secondary antibodies conjugated with horseradish peroxidase for $30 \mathrm{~min}$ at room temperature. Immunoreactions were detected with Super Signal Ultra Chemiluminescent substrate (Pierce, Rockford, IL, USA) by using ID Image Analysis software Version 3.6 (Eastman Kodak Company, Rochester, NY, USA). The western blot analysis for stemness markers, which is performed in these studies, is crude indication of stemness.

\section{Immunostaining for Proliferative Index}

The proliferative index (PI) in the paraffin-embedded tissue sections of tumor xenografts in nude mice was measured by immunostaining of proliferating cell nuclear antigen (PCNA) followed by counting the immunostained cells (DAB positive) versus hematoxylin-stained cells using software (NIS elements BR 4.13.04) and Image Pro Premier software attached with the Nikon imaging microscope system. The immunostaining was carried out according to our previous method. ${ }^{22}$ The PCNA labeling index was calculated as a mean DAB-positive tumor cells/field. The mean and s.d. values were derived from five tumor-bearing animals of each group with at least five sections from each tumor sample. Per mouse/sample, 5-10 PCNA hot spot areas of each section were analyzed.

\section{Anchorage-Dependent Growth (ADG) Assay}

ASA $(5.0 \mathrm{mM})$ pretreated for $72 \mathrm{~h}$ or DMSO alone pretreated (control) BC cells $(2$ cells $/ \mu$ l) were plated in 6-well plate in triplicate (3-wells/exp). Following seeding, cells were exposed to ASA (2.5-5.0 mM) or vehicle for 7 days and colonies were stained with $0.2 \%$ crystal violet in $80 \%$ methanol. ${ }^{23}$ After taking photographs, the colonies were counted and then they were dissolved in $10 \%$ acetic acid and OD was measured at $600 \mathrm{~nm}$ using a VMax Microplate Reader with the current version of SoftMax Pro (Molecular Devices).

\section{Anchorage-Independent Growth (AIG) Assay}

AIG of ASA pretreated and untreated BC cells was assessed by a colony formation assay in soft agar using Cyto-Select 96Well Cell Transformation Assay Kit (Cell Biolabs, San Diego, CA, USA) following the manufacturer's instructions. In brief, cells $\left(10^{4}\right.$ cells/well $)$ were thoroughly mixed in $2 \times$ DMEM/ $20 \%$ FBS containing $0.4 \%$ agar and seeded on the top of a layer of $2 \times$ DMEM $/ 20 \%$ FBS containing $0.8 \%$ agar and were allowed to solidify. After solidification of agar, DMEM/10\% FBS with or without ASA was added on the top of the agar. The cells were incubated at $37^{\circ} \mathrm{C}$ in a humidified incubator with $5 \% \mathrm{CO}_{2}$ in the air. The complete medium was added every day to keep the top layer moist, and 2 weeks later cells were stained with iodonitrotetrazolium chloride for colony visualization and counting. In addition, to measuring AIG, the agar layers were dissolved and lysed. Then, $10 \mu \mathrm{l}$ of the lysed solutions of each well was mixed with CyQuant and the fluorescence was read at $485 / 520 \mathrm{~nm}$.

\section{In Vitro Mammosphere Assay}

A mammosphere assay was performed as described elsewhere ${ }^{24,25}$ with some modifications to overcome the overdose effect of ASA. Briefly, MDA-MB-231 cells or MCF-7 cells were labeled with Nanoshuttle ${ }^{\mathrm{TM}}$-PL (an animal-originfree, polylysine-based nanoassembly that delivers magnetic nanoparticles to cells to manipulate with magnetic field; nano3D Biosciences, TX, USA). Labeled or unlabeled cells were plated as single-cell suspensions $(2 \mathrm{cells} / \mu \mathrm{l})$ in Mammocult medium containing Mammocult proliferation supplements, $4 \mu \mathrm{g} / \mathrm{ml}$ of heparin, and $0.48 \mu \mathrm{g} / \mathrm{ml}$ of hydrocortisone (Stem Cell Technologies) on ultralow attachment plates (Corning, Acton, MA, USA). The single-cell suspension cultures were allowed to grow for different times (see Figure legends) in the presence or absence of ASA to form mammospheres. Before ASA treatment every day, a magnetic drive was placed underneath the plate containing labeled cells to hold the spheres in place while removing the old media with fresh media containing ASA $(5.0 \mathrm{mM})$ or an equal volume of DMSO (control). The mammosphere formation was observed at different times and photographs were taken using a Leica photomicroscope, and sizes of the mammospheres were calculated using NIS-Elements BR imaging software attached to the microscope.

\section{Limiting Dilution Assay for Sphere-Forming Efficacy In Vitro}

The limiting dilution assay was performed as described earlier ${ }^{26}$ with little modification. Briefly, ASA- or DMSOpreexposed MDA-MB-231 cells were dissociated and seeded with different dilutions in ultralow attachment plates containing $2 \mathrm{ml}$ Mammocult media. After 7 days, numbers and size of spheres were calculated from each dilution.

\section{In Vitro Migration Assay}

The chemotaxis assay was carried out using a modified Boyden chamber technique as described previously. ${ }^{27}$ Briefly, untreated and ASA-treated BC cells (10 000 cells/well) were added to the upper chambers of the Boyden chambers containing DMEM and incubated without or with $5.0 \mathrm{mM}$ ASA in the lower chamber containing $10 \%$ FBS for $24 \mathrm{~h}$ at $37^{\circ} \mathrm{C}$ in a $\mathrm{CO}_{2}$ incubator. The migrating cells that were attached to the outer surface of the chamber were stained with a crystal violet solution. Crystal violet-stained cells were solubilized with $10 \%$ acetic acid and quantitated in Microplate reader at $600 \mathrm{~nm}$ using VMax Microplate Reader with current version of SoftMax Pro (Molecular Devices). Three wells were examined for each condition and the experiments were repeated three times. 


\section{Luciferase Activity Assay}

Cultured MDA-MB-231 cells were transfected with pLightSwitch-Prom reporter plasmid containing TGF $\beta$-1 promoter (Switchgear Genomics, CA, USA) or vector alone (negative/ background control), using Neon Transfection System (Life Technologies), following the manufacturer's protocol. Transfected cells were then treated with $5 \mathrm{mM}$ ASA or DMSO alone (controls) for $48 \mathrm{~h}$, and luciferase assay was performed using Dual-Glo Luciferase Assay kit (Promega, WI, USA). Luminescence was monitored by Glomax ${ }^{\mathrm{TM}}$ Luminometer (Promega).

\section{Mouse Xenograft Experiment}

The animal studies were conducted according to the approved Guidelines of the Animals Care and Use Committee of Kansas City VA Medical Center. Female athymic nude mice (nu/nu) were obtained from Charles Rivers (Wilmington, MA, USA) and maintained in a pathogen-free facility. The mice used for the xenograft studies were $6-8$ weeks old. We designed two sets of experiments. To study the therapeutic value of aspirin, MDA-MB-231 cells $\left(1 \times 10^{6} /\right.$ mouse $)$ suspended in $0.1 \mathrm{ml}$ PBS and $0.1 \mathrm{ml}$ matrigel were injected subcutaneously (s.c.) into the right hind leg of each mouse ( $n=10$ /group). After development of a palpable tumor, ASA treatment was started. The treatment group received aspirin orally at $75 \mathrm{mg} / \mathrm{kg} /$ day for 5 days per week, dissolved in $10 \mathrm{ml}$ of milk (Peptamen (Nestle)) for $12 \mathrm{~h}$ during the dark for 15 days. The control group received only milk. The selected ASA dose was the human equivalent dose (HED) of $<360 \mathrm{mg} / 60 \mathrm{~kg} /$ day human adult, the traditional low-to-moderate dose of ASA prescribed to patients for pains or other pathobiological reasons. The HED was calculated using the following chemical formula: ${ }^{28}$

HED $(m g / K g)=$ Animal dose $(m g / K g)$ multiplied by Animal Km/Human Km.

Mouse $K_{\mathrm{m}}=3$; human $K_{\mathrm{m}}=37$.

As we fed mice $75 \mathrm{mg} / \mathrm{kg} /$ day for 5 days per week, the HED would be $\sim 360 \mathrm{mg} / 60 \mathrm{~kg} / \mathrm{day}$ human adult dose or less. This acute dose can be considered traditional low-to-moderate dose of ASA.

Tumor size was monitored three times weekly. Tumor volume was calculated using Studylog animal study management software (Studylog, San Francisco, CA, USA). After 15 days, mice were killed and tumors were dissected; the weights were measured and stored at $-80^{\circ} \mathrm{C}$.

To investigate the protective/preventive role of ASA in tumor development, ASA was administered to the treated group of mice for 10 days, and thereafter tumor cells were injected s.c. into the right hind leg of the mice, and ASA treatment was continued for an additional 15 days. Tumor volume was taken three times weekly as described earlier. Mice were monitored daily for adverse effects and were killed when any mouse seemed moribund.

\section{Primary Xenograft Cell Culture}

The ASA-treated (pre and post) and control (peptamen alone) tumors from xenograft mice were collected and washed in serum-free DMEM, then trypsinized for $3 \mathrm{~h}$ and allowed to grow in DMEM containing 10\% FBS. Cell morphology was then studied under microscope.

\section{Statistical Analysis}

All data are presented as the mean \pm s.d. of ' $n$ ' independent measurements, as indicated in the corresponding figure legends. Statistical comparisons between treated and untreated control groups were calculated by Student's $t$-tests using GraphPad Prism6, and multiple groups were determined by ANOVA test. A value of $P<0.05$ was considered significant.

\section{RESULTS \\ Dose-Dependent Inhibitory Effect of ASA on BC Cell Viability and Growth Is Mediated via Apoptosis}

Previously, it has been reported that therapeutic dose levels between 1 and $5 \mathrm{mM}$ of ASA are ideal for treating chronic inflammatory diseases, ${ }^{29-32}$ whereas a dose of ASA at $2.5-10 \mathrm{mM}$ is required to prevent growth of various cancer cells under tissue culture conditions via possibly inducing pro-apoptotic signals. ${ }^{3-35}$ However, minimum and incomplete information is available about the effect of ASA on human BC cell viability, growth, and differentiation. Thus, we initiated this study with the aim to determine the dosedependent effect of ASA on viability of estrogen receptor (ER)-positive BC cells and TNBC cells. To do so, MCF-7 $\left(\mathrm{ER}^{+}\right.$) and MDA-MB-231 (TNBC) cells were exposed to different doses of ASA (ie, $0-5 \mathrm{mM}$ ) for $72 \mathrm{~h}$. Cell viability was determined using crystal violet assay. We found that ASA significantly decreased MCF-7 and MDA-MB-231 cell viability in a dose-dependent manner as compared with the control (DMSO alone) group (Figure 1a). The significant inhibitory effect of ASA was first detected at $1000 \mu \mathrm{M}$ $(0.18 \mathrm{mg} / \mathrm{ml})$ in both cell lines that can be considered as corresponding to low-dose ASA in tissue culture conditions. Inhibition at $50 \%\left(\mathrm{IC}_{50}\right)$ was obtained with a $5 \mathrm{mM}$ dose for MDA-MB-231, whereas lower than $\mathrm{IC}_{50}$ was observed in the case of MCF-7 cells at $2.5 \mathrm{mM}$ (Figure 1b). The effect of ASA $(5.0 \mathrm{mM})$ on $\mathrm{BC}$ cell viability was further confirmed using Trypan blue exclusion assay (Supplementary Figure S1). A similar inhibitory effect of ASA was also observed in other cell lines (Supplementary Figure S2). Interestingly, we found that MCF-7 cells are sensitive to ASA at $50 \mu \mathrm{M}$ dose, whereas MDA-MB-231 cells are sensitive at $1000 \mu \mathrm{M}$. Thus, subsequent studies were carried out at the 2.5 or $5.0 \mathrm{mM}$ dose. The nonsignificant changes in cell viability using crystal violet assay or Trypan blue exclusion assay were observed following ASA treatment in these cells at 24 or $48 \mathrm{~h}$ (data not included).

Next, we determined the effect of different doses of ASA on MCF-7 and MDA-MB-231 cell proliferation using BrdU ELISA. We found that ASA at the doses of 2.5 and $5.0 \mathrm{mM}$ 

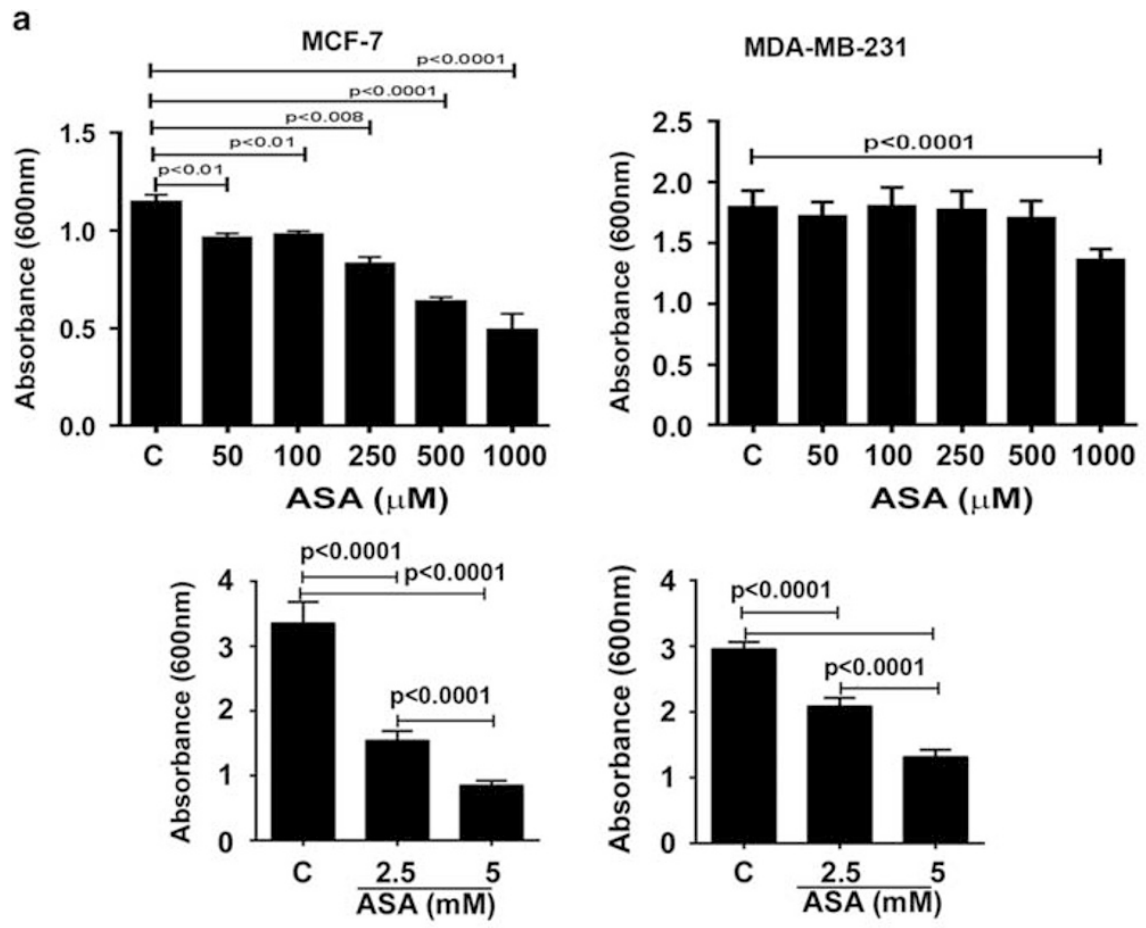

b

MCF-7

MDA-MB-231
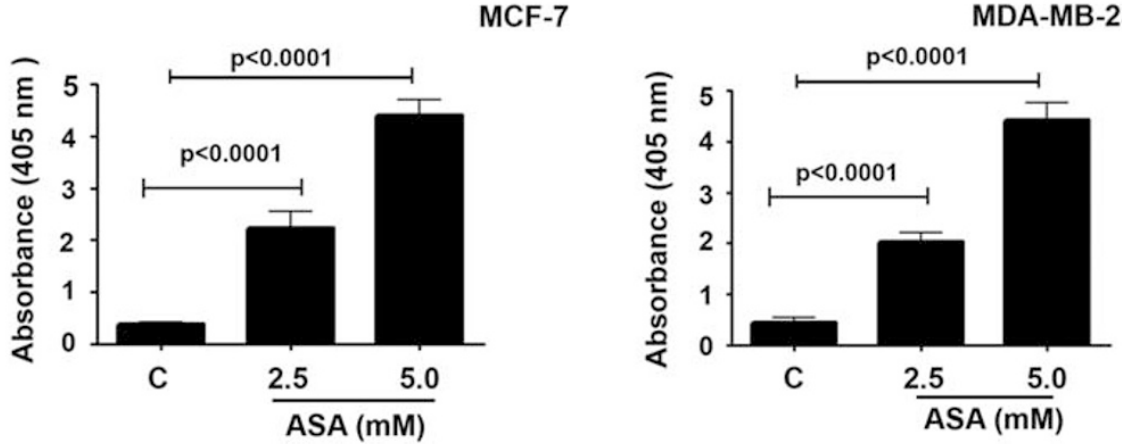

C
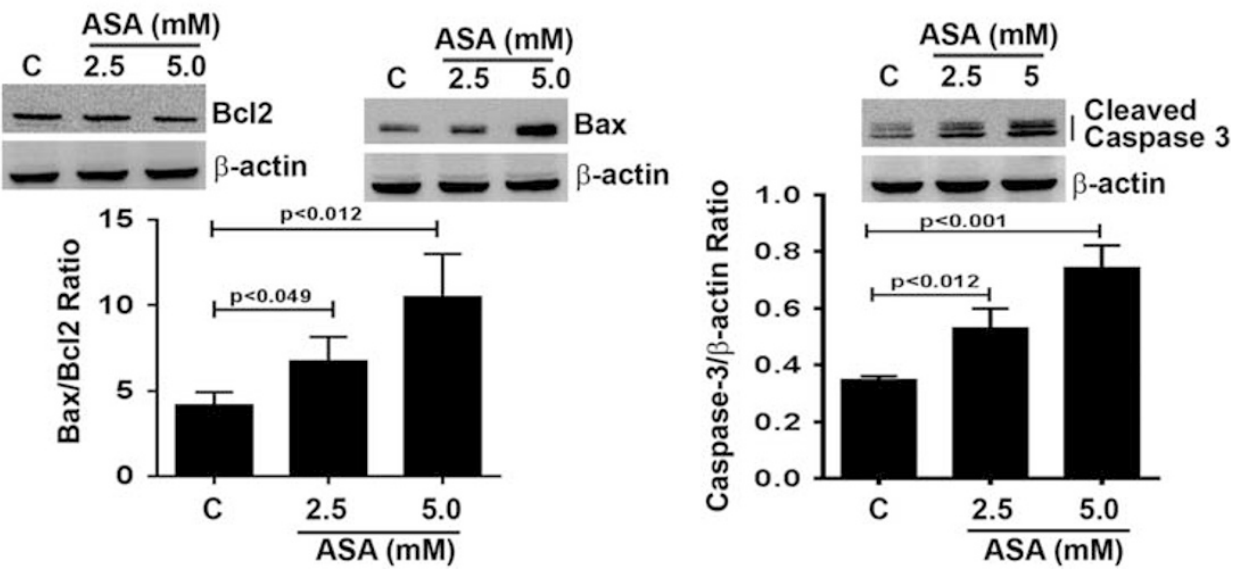

Figure 1 ASA decreases different BC cell viability through apoptosis. (a) Dose-dependent effect of ASA on viability of MCF-7 and MDA-MB-231 cells after $72 \mathrm{~h}$ of treatment. Cell viability was measured by crystal violet assay. (b) BC cells were treated with different doses of ASA for $72 \mathrm{~h}$ and apoptosis was determined using cell death detection ELISA kits. Data in (a) and (b) show mean \pm s.d. and are representative of at least eight independent experiments. (c) Western blot detection of Bcl2, Bax, and cleaved Caspase-3 proteins in ASA-treated and DMSO-treated (Control) MDA-MB-231 cells. $\beta$-Actin was used as a loading control. The error bars indicate the changes in the ratio of Bax to Bcl-2 protein levels in ASA-treated and control samples. Error bars represent mean \pm s.d. Unpaired two-tailed Student's $t$-test was used for statistical analysis. 
significantly reduced BrdU incorporation in both MCF-7 and MDA-MB-231 cells compared with DMSO after $48 \mathrm{~h}$ of treatment (Supplementary Figure S3). Collectively, these studies indicate that ASA promotes growth arrest (cytostatic) and cell killing (cytotoxic) in BC cells in a dose- and timedependent manner.

To study whether the inhibition of cell viability and proliferation by ASA is because of apoptosis, ELISA-based apoptosis assay was performed. As shown in Figure 1b, ASA significantly increased the apoptotic cell death in a dosedependent manner in both MDA-MB-231 and MCF-7 cells. Next, we ascertained whether ASA modulates the levels of Bax, Bcl-2, and Caspase-3, the prime regulators of apoptosis. To do so, MDA-MB-231 cells were treated with different doses of ASA or DMSO alone (control) for $72 \mathrm{~h}$ and levels of $\mathrm{Bcl}-2$, Bax, and Caspase- 3 proteins were determined using western blotting. In cells treated with ASA, we observed a significant increase in Bax/Bcl-2 ratio and Caspase-3 levels in a dose-dependent manner in MDA-MB-231 cells as compared with controls (Figure 1c).

COX-2 protein, which is overexpressed in MDA-MB-231 cells, inhibits apoptosis in various cancer cells through the regulation of multiple pathways including Fas-Caspase-3mediated apoptosis. ${ }^{36-38}$ Given the constitutive overexpression of COX-2 in MDA-MB-231 cells, we postulated that ASA may negatively regulate COX-2 expression to promote apoptosis signals. However, this is not the case as ASA was unable to regulate COX-2 expression at protein level in MDAMB-231 cells (Supplementary Figure S4). Thus, consistent with previous work, ${ }^{33-35}$ it appears that the $\mathrm{BC}$ cell death by ASA is mediated by apoptosis through the regulation of Bax/ Bcl2 and Caspase-3 system. Although the role of COX-2 signaling in this event is unclear, the involvement of this signaling pathway cannot be ruled out.

\section{ASA Suppresses BC Tumor Growth in Xenograft Mouse Model}

To investigate whether ASA is effective in vivo, we determined the therapeutic effect as well as the protective effect of ASA in a subcutaneous tumor xenograft model of nude mice (Figure 2). To investigate the therapeutic role of ASA, we considered MDA-MB-231 cells because these cells are very aggressive and generate tumors in the nude mice rapidly without estrogen supplements. Cells $\left(1 \times 10^{6}\right.$ cells/mouse $)$ were mixed with an equal volume of matrigel (BD Biosciences), and injected s.c. into the nude mice to develop a tumor. ASA treatment was begun after subcutaneous tumor was palpable (Figure 2a). Compared with the untreated control mice, the volumes of the tumors in ASA-treated mice were significantly $(P<0.001)$ smaller $(\sim 35-60 \%$ inhibition $)$ after 15 days of ASA treatment (Figure 2a), and results are reflected in cell proliferation marker PCNA immunohistochemical analysis in tissue samples (15-day treatment) (Figure 2b). We found that ASA induced apoptosis in MDA-MB-231 xenograft tumors when we assessed cleaved
Caspase- 3 by western blotting in 15-day-treated frozen tissues (Figure $2 \mathrm{~b}$ bottom panel), suggesting that ASA delayed tumor outgrowth by inducing apoptosis. This mirrors the in vitro sensitivity of ASA in BC cells. To explore the protective role, pre-ASA-treated (10 days before cell inoculation) mice were injected with MDA-MB-231 cells $\left(1 \times 10^{6}\right.$ cells/mice $)$ for tumor development and ASA treatment was continued for the next 15 days (Figure 2c). We found that ASA not only significantly inhibited tumor outgrowth, but also delayed the formation of a palpable tumor (Figures $2 \mathrm{c}$ and $\mathrm{d}$ ).

\section{TICs/CSCs Are Sensitive to ASA}

TICs/CSCs seem to be responsible for initiation, metastasis, as well as resistance to chemotherapy. ${ }^{39,40}$ The goal of our ongoing studies is to eradicate BTICs. Thus, we next asked whether ASA might be an inhibitor of BTIC growth. To address this question, first, we determined the effect of ASA (before and after treatment) on ADG of mesenchymal-type/basal-like MDA-MB-231 TNBC cells (Figure 3a). In an ADG assay, we found large numbers of colonies with high cell density in the control set (C), whereas significantly fewer colonies were formed by pre-ASA-treated (T1) as well as pre- and post-ASAtreated (T2) MDA-MB-231 cells (Figure 3b).

Next, we determined the ability of MDA-MB-231 cells to grow in an AIG manner in the presence or absence of ASA. We observed that MDA-MB-231 cells, which have efficient colony formation skill in soft agar under normal environment (media containing DMSO only), lost the ability to form colonies after ASA treatment (Figure 3c). Interestingly, cells that survived from ASA were unable to or minimally able to form colonies on agar after reseeding on agar (data not shown).

Under nonadherent culture atmospheres, MCF-7 (luminallike, $\mathrm{ER}^{+}$) and MDA-MB-231 (basal-like, TNBC) cell lines are able to form sphere-like structures (mammospheres) ${ }^{41}$ that are unique surrogate in vitro assays for the detection of stemness with self-renewal properties. ${ }^{7}$ Thus, in order to determine the role of ASA on BITC self-renewal/stemness, we decided to evaluate the effect of ASA on sphere formation. MCF-7 or MDA-MB-231 cells were grown in nonadherent culture atmospheres for 6 and 10 days in the presence or absence of ASA ( $5.0 \mathrm{mM})$, and the newly formed mammospheres and their sizes were then counted. Treatment with ASA reduced the number of mammospheres and decreased the size of each sphere in a time-dependent manner as compared with controls (Figure 4a). Next, as shown in Figure 4b, MDA-MB-231 cells were treated with ASA $(5.0 \mathrm{mM})$ or DMSO alone (control) for 8 days under regular adherent culture atmospheres. These cells were then grown in nonadherent culture conditions in the absence (PT) or presence (T) of ASA $(5.0 \mathrm{mM})$ for 10 days, and we characterized mammosphere formation in vitro. Both pre-ASA-treated (PT) and pre- and post-ASA-treated (PT+T) cells showed significant reduction in mammosphere formation compared with control cells (Figure 4c). Moreover, ASA-treated 
a

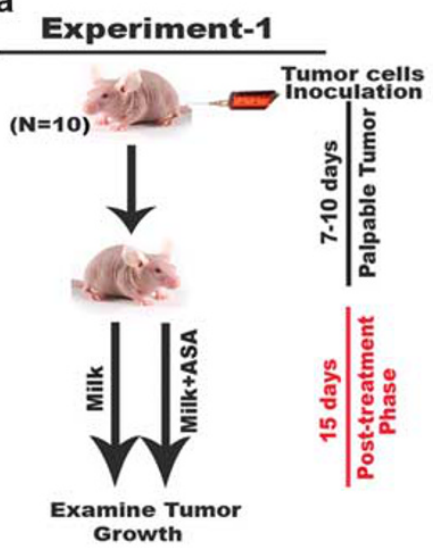

c

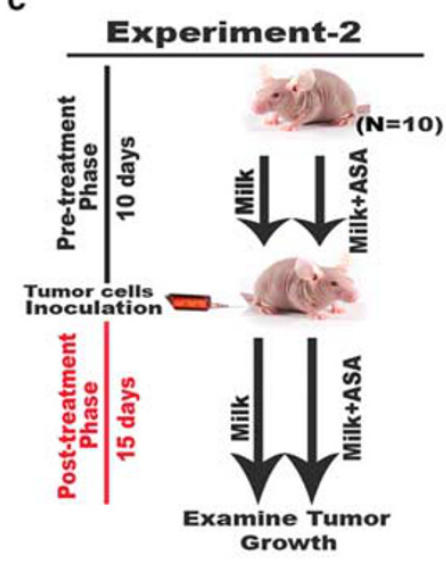

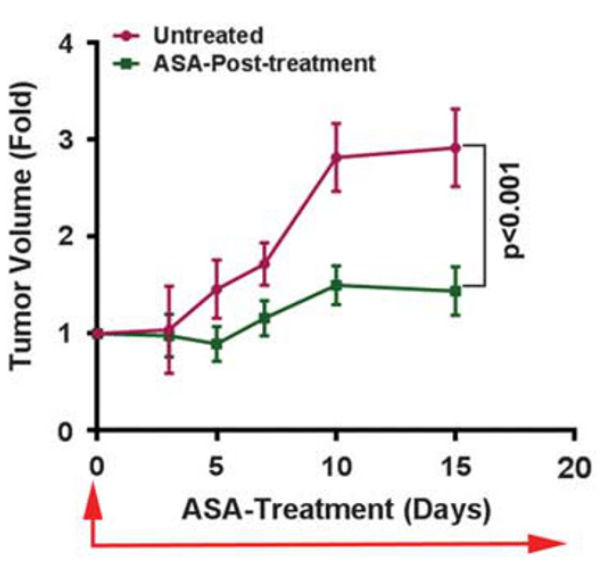

b Control
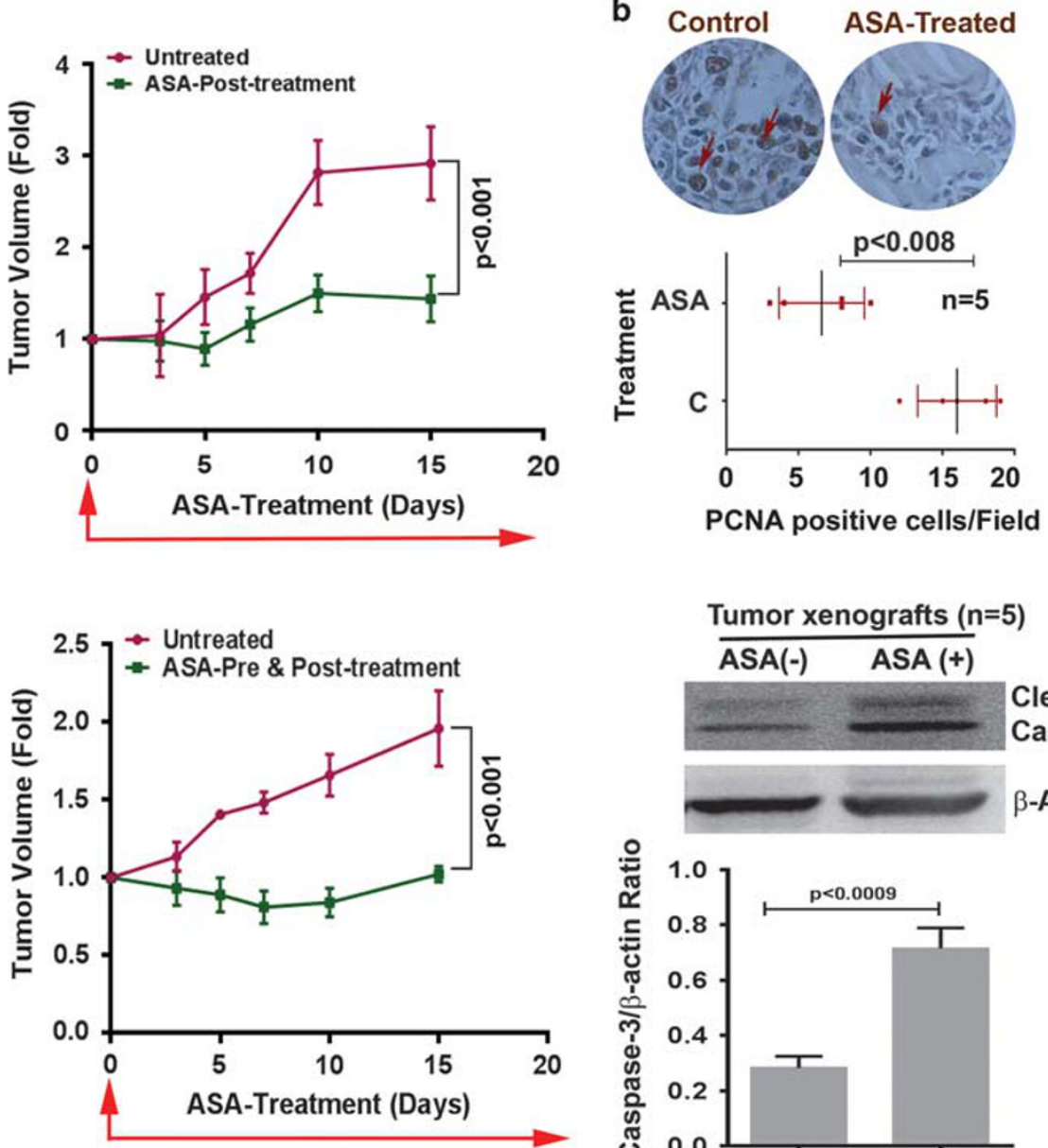

Tumor xenografts ( $\mathrm{n}=5$ )

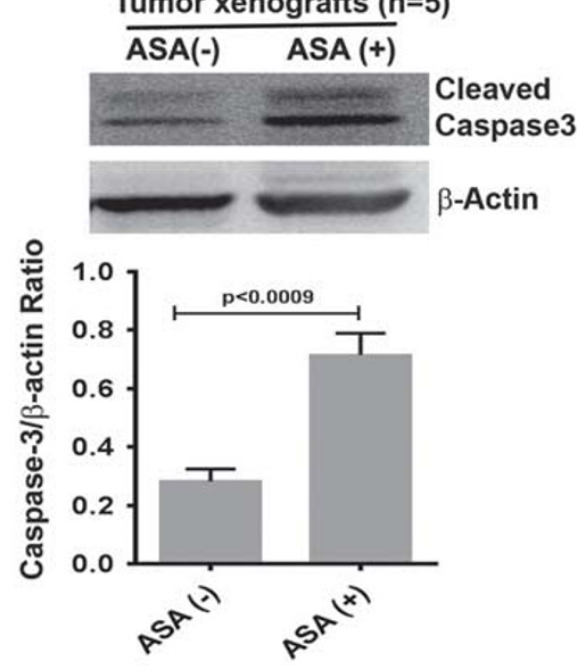

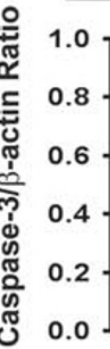
Caspase3

Treatment

d

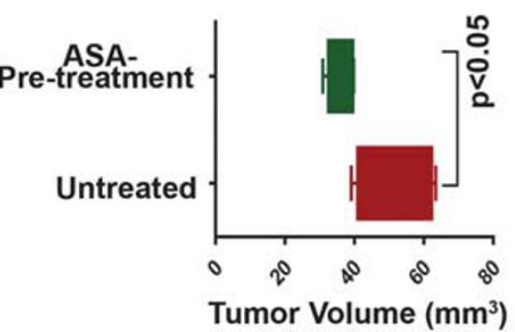

Figure 2 Differential effect of ASA on growth of MDA-MB-231 tumor mouse xenograft model. (a, left panel: a schematic representation of experiment 1): MDA-MB-231cells $\left(1 \times 10^{6}\right)$ /matrigel were implanted subcutaneously into athymic female nude mice. When tumors became palpable, mice were fed ASA $(75 \mathrm{mg} / \mathrm{kg} / \mathrm{day}$ ) with peptamen (milk) for 15 days. (a, right panel) Mean tumor volume (fold) is presented as the effect of ASA after treatment. Error bars present mean \pm s.d. Red arrow indicates when tumor became palpable and treatment starts. (b, upper panel) Immunohistochemical localization of PCNA in paraffin-embedded tissue sections of ASA-treated and control MDA-MB-231 tumor xenograft. Error bars present mean numbers \pm s.d. of PCNA-positive cells/field of five fields. (b, bottom panel) Detection of cleaved-Caspase-3 protein using western blotting in protein lysates from ASA-treated (ASA (+)) and control (ASA (-)) tumor samples. Analyses were performed in five different samples. (c, left panel) A schematic representation of experiment 2. (c, right panel) Tumor volume (fold) in MDA-MB-231 tumor xenograft mice after pre- and post-ASA treatment or no treatment. Data are presented as mean \pm s.d. Red arrow indicates when tumor became palpable in ASA-pretreated mice. (d) Volume of the palpable tumors in ASA-pretreated and untreated mice. Data are presented as mean \pm s.d.

cell-generated mammospheres were markedly smaller than those generated from controlled cells. Next, the primary mammospheres of the control and PT cells were dissociated and plated $(2$ cells $/ \mu \mathrm{l})$ over multiple passages and the resulting mammospheres were quantified. Expectedly, primary mammospheres of DMSO-controlled derived cells generated almost equal numbers and marginally smaller than secondary mammospheres (Figures $4 \mathrm{~d}$ and e), of which dissociated cells formed tertiary mammospheres (data not shown). In contrast, pretreatment of ASA reduces or eliminates the secondary sphere-forming ability of these cells (Figures $4 \mathrm{~d}$ and e), with no generation of mammospheres over successive 
b

(ADG)

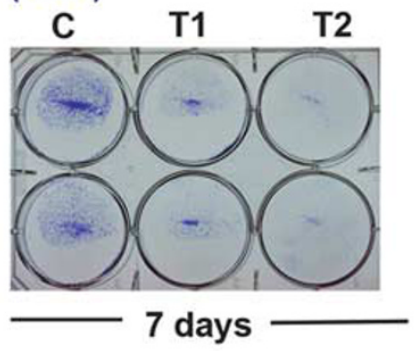

7 days (ADG)

—15 days (AIG) -
T1

T2

C

7 days

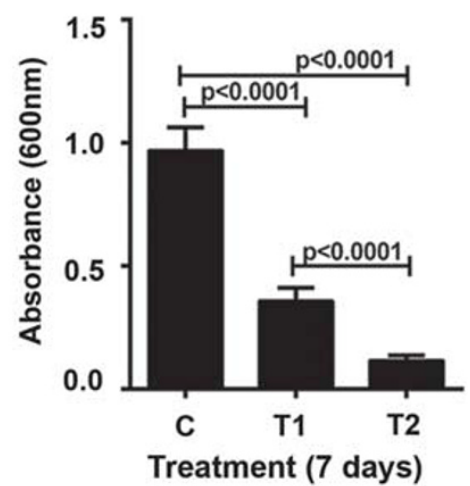

C

(AIG)
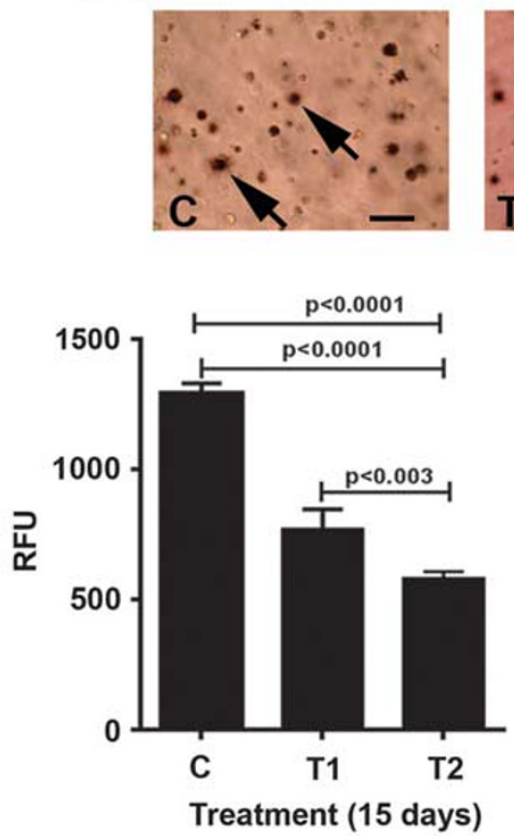
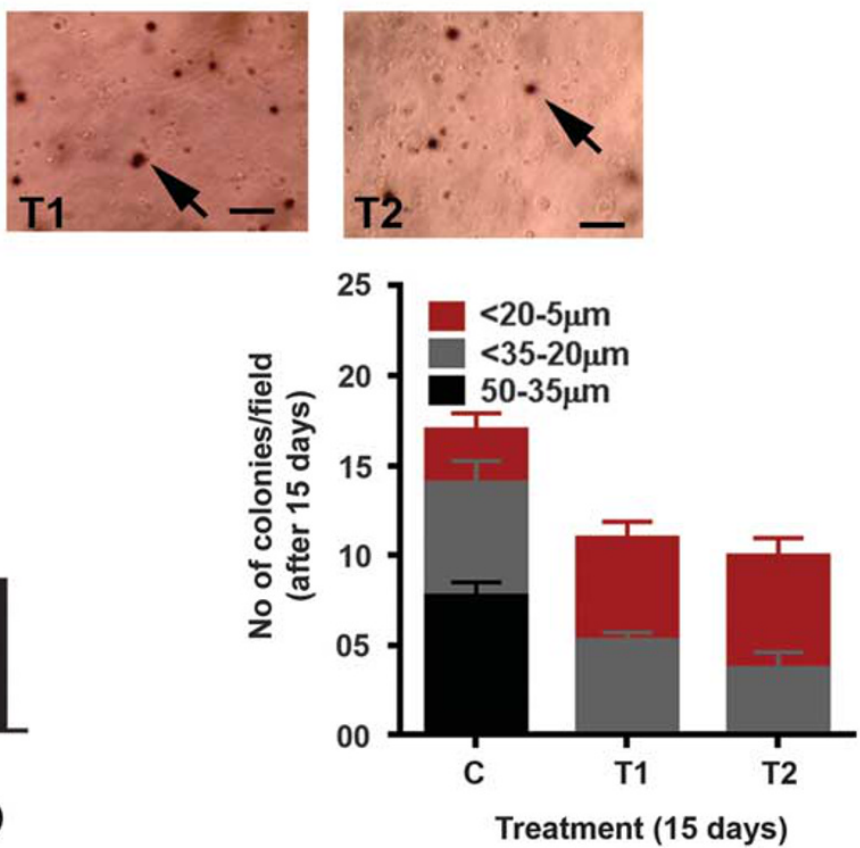

Figure 3 MDA-MB-231 cells and their BTICs/BCSCs are sensitive to ASA. (a) Schematic representation of the experimental designs. (b) ADG assays of MDA-MB-231 cells treated with ASA as described in (a). Error bars indicate mean \pm s.d. and represent at least three independent experiments. (c) AIG assays of MDA-MB-231 cells treated with ASA as described in (a). (c, upper panel) Representative images of AIG in different treatment environments. Scale bar $=50 \mu \mathrm{m}$. (c, lower panel) Bar graphs indicate the number of viable neoplastic cells (left) and number of colonies (right) in ASA-treated or control samples. Error bars indicate mean \pm s.d. and represent at least three independent experiments.

passages (data not shown). Collectively, these studies indicate that ASA prevents BTICs growth in both luminaland basal-type BC cells by blocking self-renewal capacity of these cells. Similar results were obtained when we computed the effect of ASA on sphere-forming efficiency of MDA-MB-231 cells using in vitro limiting dilution assay (Supplementary Figure S5).

\section{ASA Suppresses In Vitro BC Cell Migration}

Because cell migration/motility is intimately wired to invasion and metastatic growth to distant organs, ${ }^{42}$ we next sought to determine whether ASA can modulate in vitro BC cell migration. To do so, MCF-7 and MDA-MB-231 cells were preexposed to ASA for $72 \mathrm{~h}$ followed by in vitro migration using a transwell Boyden chamber in the presence or absence of ASA as illustrated in Figure 5a. Results showed that migration of MDA-MB-231 and MCF-7 cells were significantly blocked by ASA treatment compared with DMSO controls (Figure 5b). Interestingly, both MDA-MB-231 cells and MCF-7 cells could not regain their migration property even after withdrawal of ASA for $48 \mathrm{~h}$ (Figure 5b, T3). We also tested the antimigratory role of ASA on other TNBC cells, HCC-70 and 4T1, and we found that ASA significantly decreased migration of these cell lines (data not shown). Therefore, ASA is a potent inhibitor of $\mathrm{BC}$ cell migration in vitro. 
a

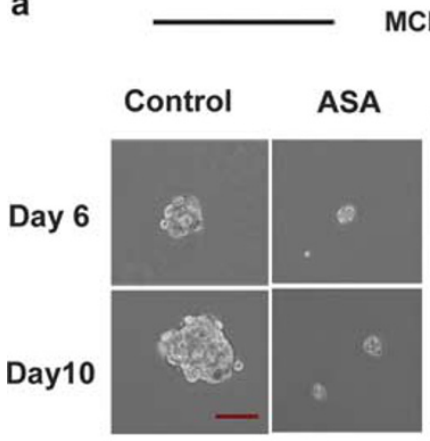

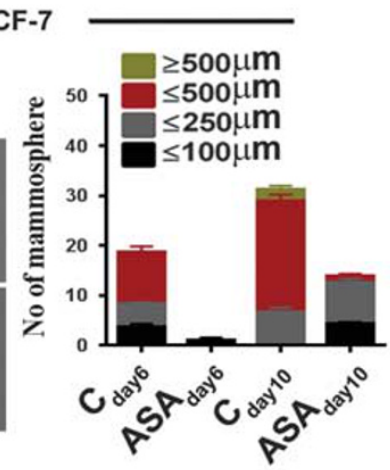

Treatment

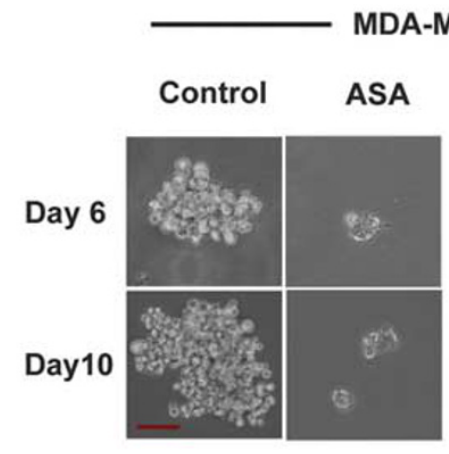

.

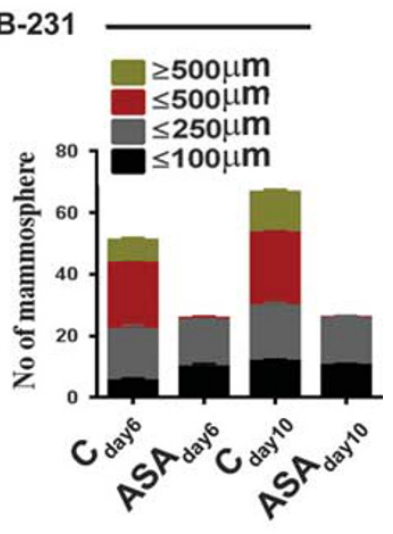

Treatment

b

\section{Dissociation}

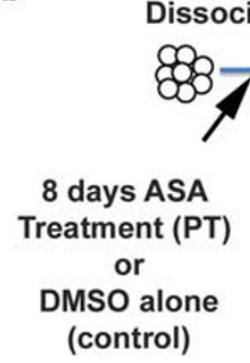

(control)

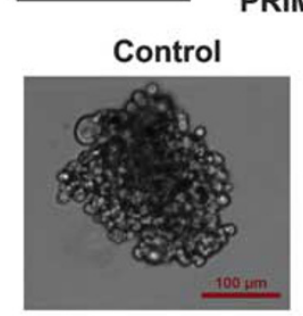

\section{PRIMARY SPHERE}
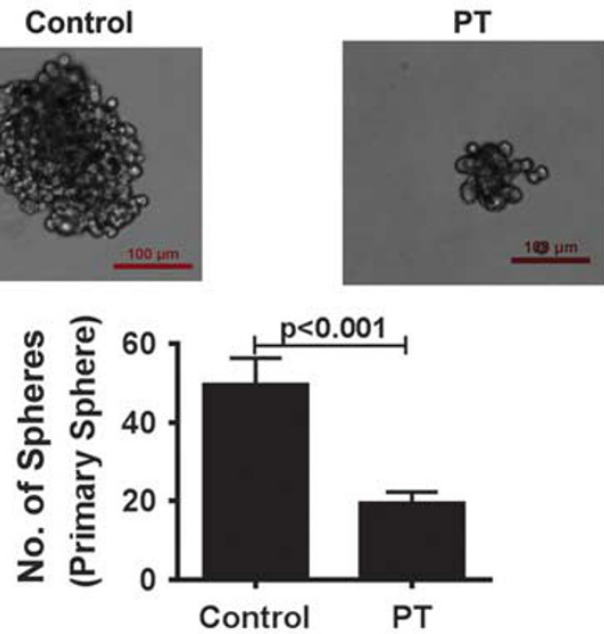

Treatment

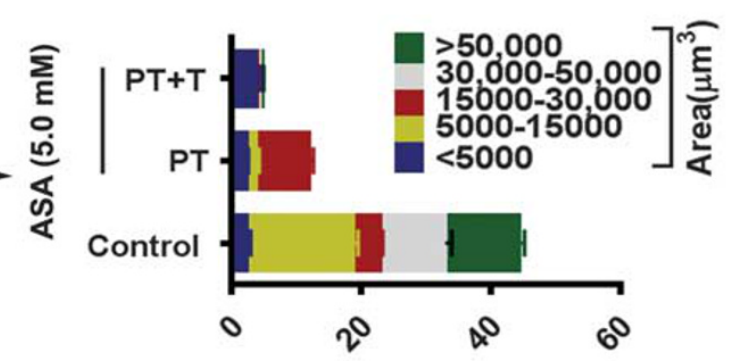

No. of Spheres

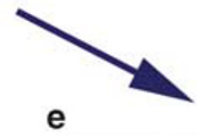

e
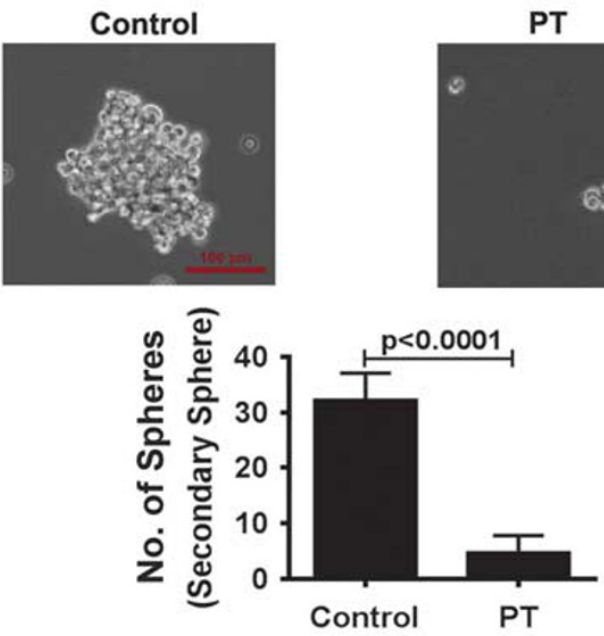

Treatment

Figure 4 Effect of ASA on sphere formation and self-renewal of BTICs/BCSCs. (a) Effect of ASA (5.0 mM) or DMSO alone (control) on the mammosphereforming ability of MCF-7 and MDA-MB-231 cells was detected after day 6 and day 10 of treatments. Photographs illustrate structure and size of mammospheres in ASA-treated and control cells. Bar graph shows the distribution of different-sized mammospheres $(\mu \mathrm{m})$ in treated and untreated groups. Scale bar $=50 \mu \mathrm{m}$. (b) The schematic representation of experimental design. Sphere-forming ability of ASA-pretreated (PT, $5.0 \mathrm{mM}$ ASA for 8 days) residual MDA-MB-231 cells were analyzed in the absence (PT) or presence (PT+T) of ASA in the mammosphere culture. (c) The multiple color bar graphs indicate the distribution of spheres of different sizes in different treatment conditions. (d) Self-renewal capacity of ASA-preexposed cells were measured in different passages. (e) Self-renewal capacity of secondary passage spheres of ASA-treated and untreated dissociated cells from 1 st passage. Scale bar $=100 \mu \mathrm{m}$. Error bars represent mean \pm s.d. 
a

$$
\begin{aligned}
& \text { C ( Untreated control) } \\
& \text { Cell culture } \longrightarrow \text { In vitro migration }
\end{aligned}
$$

T1 (Treatment profile 1/Direct Effect) Cell culture $\longrightarrow$ In vitro migration

$$
\text { No ASA Treatment ASA Treatment }
$$

T2 (Treatment profile 2/Post-effect) Cell culture $\longrightarrow$ In vitro migration ASA Treatment for $72 \mathrm{~h}$ ASA Treatment

T3 (Treatment profile 3/Residual cells)

Cell culture $\longrightarrow$ In vitro migration

$\uparrow$
ASA Treatment for $72 \mathrm{~h}$ No ASA Treatment

then withdrawal for $48 \mathrm{~h}$

C
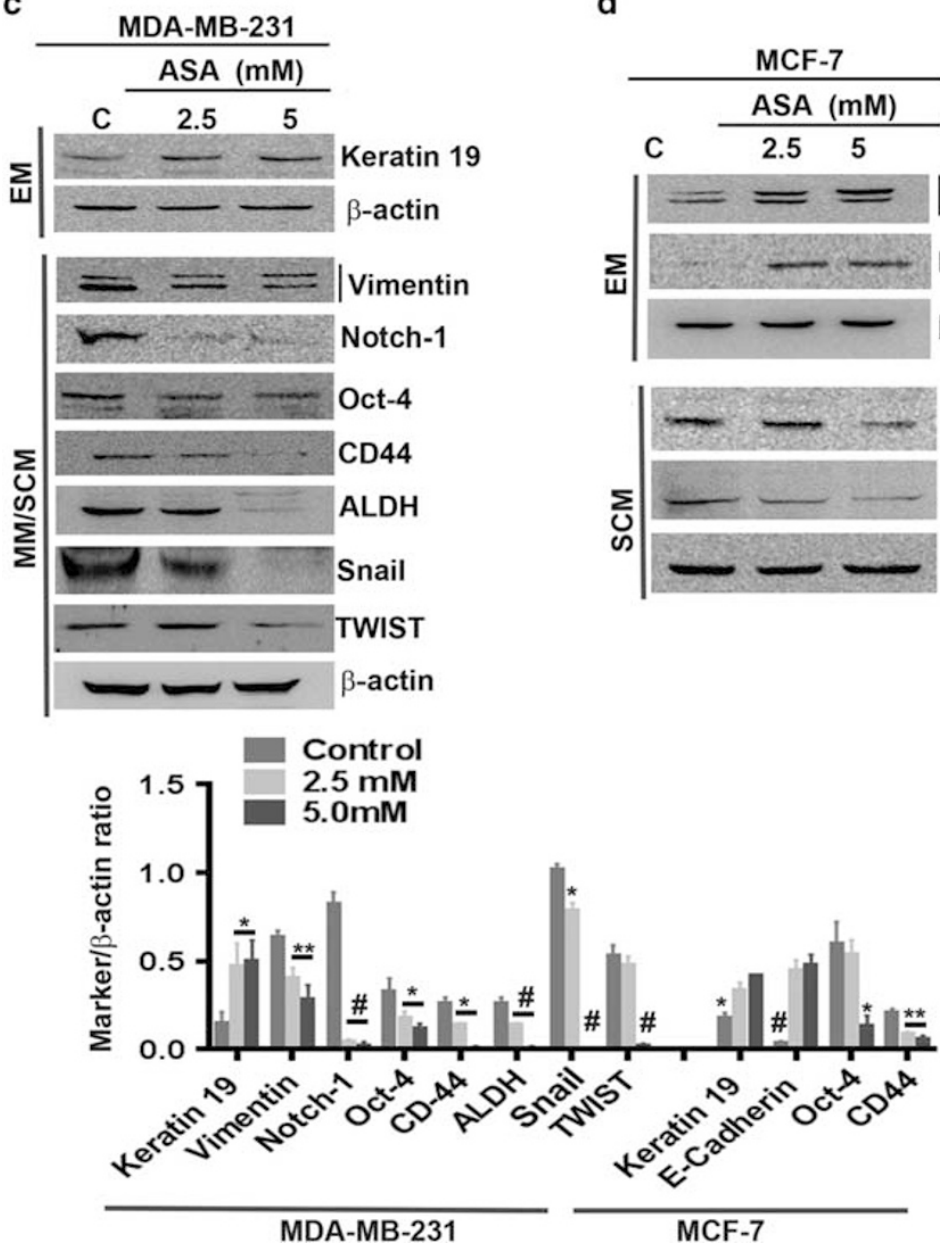

b

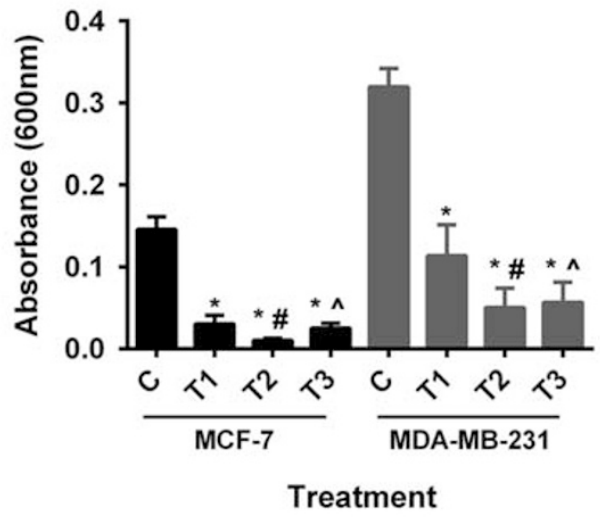

d
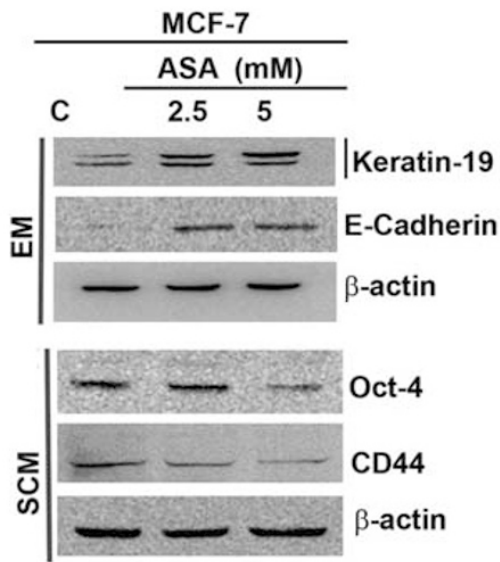

Figure 5 ASA suppresses in vitro migration and reverses EMT to MET in BC cells. (a) Schematic representation of the experimental designs. (b) MCF-7 and MDA-MB-231 cells were treated with ASA or DMSO alone (control) for $72 \mathrm{~h}$. Cells were allowed to migrate through the membranes of a modified Boyden chamber for $24 \mathrm{~h}$ in the presence or absence of ASA. The migrated cells were measured according to the protocol indicated in the Materials and Methods section. Data show mean \pm s.d. and are representative of at least five independent experiments. ${ }^{*} P<0.001$ vs Controls (C), ${ }^{\#} P<0.002$ vs T1, $\wedge P<0.01$ vs T2. (c, d) Detection of epithelial, mesenchymal, and stem cell markers in ASA-treated and control MDA-MB-231 and MCF-7 cells by western blotting. $\beta$-Actin was used as the loading control. Data show mean \pm s.d. and are representative of at least five independent experiments. ${ }^{*} P<0.0002$ vs control; ${ }^{* *} P<0.0012$ vs control; ${ }^{\#} P<0.001$ vs control. 


\section{ASA Alters In Vitro Expression of Epithelial to Mesenchymal Transition (EMT) and Stemness Markers}

EMT and cancer stemness, which are possibly overlapping events, are necessary to increase cancer cells' invasion, metastasis, and resistance to drugs, and thus they represent a very promising therapeutic target. ${ }^{43}$ Based on our findings (Figures 3 and 4), we hypothesize that ASA may reprogram EMT to MET. To test the hypothesis we examined the impact of ASA on molecular signatures taken by cancer cells during the EMT reprogramming process. We found that ASA treatment, in a dose-dependent manner, significantly downregulates the expression of mesenchymal markers (ie, vimentin) and stem cell markers (ie, Notch, CD44, ALDH, Snail, TWIST, and Oct4), whereas it upregulates the expression of epithelial markers (ie, Keratin-19 and E-cadherin) in MDA-MB-231 cells or MCF-7 cells or both (Figures $5 \mathrm{c}$ and d). The effect of ASA treatment on Oct4 was drastic in MCF-7 cells at $5.0 \mathrm{mM}$ as compared with MDA-MB-231 cells where the effect was the least, although significant. Although ASA treatment significantly elevated the E-cadherin level in MCF-7 cells (Figure 5d), no effect of ASA was detected on E-cadherin in MDA-MB-231 cells (data not shown). Regardless of some divergences in the effect of ASA, collectively, these findings suggest that ASA reverses the EMT process in $\mathrm{BC}$ cells through reprogramming the molecular paths.

\section{ASA Prevents MDA-MB-231 Tumor Xenograft Cell Migration and Promotes Reprogramming of MET}

We determined whether ASA treatment alters the cellular behaviors and reduces the migration potency of MDA-MB-231 residual tumor cells in vitro through the reprogramming of MET. To do so, we isolated tumor cells from both untreated and ASA-treated tumor xenografts, and grew them in appropriate tissue culture media (Figure 6a). Once the cells reached $\sim 75 \%$ confluence, we found that untreated cells made several clonal growths in vitro, whereas the clonal growth was dramatically decreased when ASA-treated tumor cells grew (Figure 6bA-C). Morphologically, under culture conditions, ASA-treated and untreated MDA-MB-231 cells or xenograft tumor-derived cells are very distinct. Untreated cells show spindle-shaped fibroblast-like structure (mesenchymal), whereas ASA-treated cells are more epithelial like in structure (Figure 6b (inset) and Figure 6c).

To determine the in vitro migration of xenograft-derived cells, we reseeded them on a modified Boyden chamber for in vitro migration assay (Figure 6a). We found that ASA-treated cells less effectively migrate toward the serum as compared with untreated cells (Figure 6d). Next, EMT markers in tumor lysates from the untreated and ASA-treated mice were analyzed by western blotting. We found that the expression of mesenchymal and stemness protein markers (ie, vimentin, Oct4, and CD44) were significantly reduced in all ASA-treated samples as compared with untreated controls where these proteins were upregulated in all samples
(Figure 6e and Supplementary Figure S6). In contrast, epithelial markers like keratin-19 were upregulated in the ASA-treated tumor samples as compared with controls. Collectively, these findings indicate a preventive role of ASA on BC progression through reversing the EMT reprogramming.

\section{ASA Suppresses TGF- $\beta$ Signaling in BC Cells}

TGF- $\beta$ can behave as both a tumor suppressor and a tumor promoter. In human cancers they often become resistant to TGF- $\beta$ growth inhibition, and secrete elevated levels of this growth factor. ${ }^{44,45}$ At this point, the role of TGF- $\beta$ switches to a tumor promoter. It is now well accepted that during early stage of breast tumor growth, TGF- $\beta$ functions as tumor suppressor, whereas at an advanced stage there is a switch of TGF- $\beta$ function toward malignant progression that increases invasive phenotypes and metastasis (reviewed $\mathrm{in}^{46}$ ). Moreover, TGF- $\beta$ signaling plays an essential role in promoting self-renewal of cancer-initiating cells. ${ }^{47}$ Given the importance of the role of TGF- $\beta$-signaling in BC progression, we sought to determine whether ASA can regulate TGF- $\beta$ and its receptor TGF- $\beta$ RII production in BC cells. To do so, we first treated MDA-MB-231 cells with ASA $(5.0 \mathrm{mM})$ for $72 \mathrm{~h}$, and the productions of TGF- $\beta$ and TGF- $\beta$ RII were determined using western blotting. We noticed a significant reduction in TGF- $\beta$ production in ASA-treated MDA-MB-231 cells as compared with controls (Figure 7a). However, ASA had no effect on TGF- $\beta$ RII production (Figure $7 b$ ). Next, we investigated whether induction of TGF- $\beta$ was at the transcriptional level. To do so, MDA-MB-231 cells were transiently transfected with a reporter plasmid driven by the TGF- $\beta 1$-promoter or vector alone, and the effect of ASA was determined using luciferase assay. ASA treatment $(5 \mathrm{mM} /$ $48 \mathrm{~h}$ ) significantly reduced the constitutive TGF- $\beta$ promoter activity in MDA-MB-231 cells (Figure 7c), suggesting that ASA-mediated reduction of TGF- $\beta$ was at the transcription level. Finally, we sought to determine the effect of ASA on SMAD4 production that is downstream of TGF- $\beta$ and plays a critical role in EMT and metastasis of BC cells. ${ }^{48,49}$ We found that SMAD4 production was blocked by ASA treatment $(5 \mathrm{mM} / 48 \mathrm{~h})$ in MDA-MB-231 cells (Figure $7 \mathrm{~d}$ ). Collectively, these studies indicate that ASA suppresses TGF- $\beta$-signaling in MDA-MB-231 BC cells.

\section{ASA Inhibits BTIC Self-Renewal and Migration via TGF- $\beta$ Signaling}

Based on the data of Figure 7, we hypothesized that ASA-induced inhibition of the self-renewal capacity of BTICs could be mediated through the regulation of TGF- $\beta$ signaling. To assess this, we plated MDA-MB-231cells $(2$ cells $/ \mu \mathrm{l})$ that were preexposed to ASA or DMSO alone (control) in the presence or absence of human recombinant TGF- $\beta$ protein (hrTGF- $\beta ; 10 \mathrm{ng} / \mathrm{ml}$ ) and then characterized the mammosphere formation ability of these cells. We found that ASA-treated cells, as expected, formed significantly fewer 


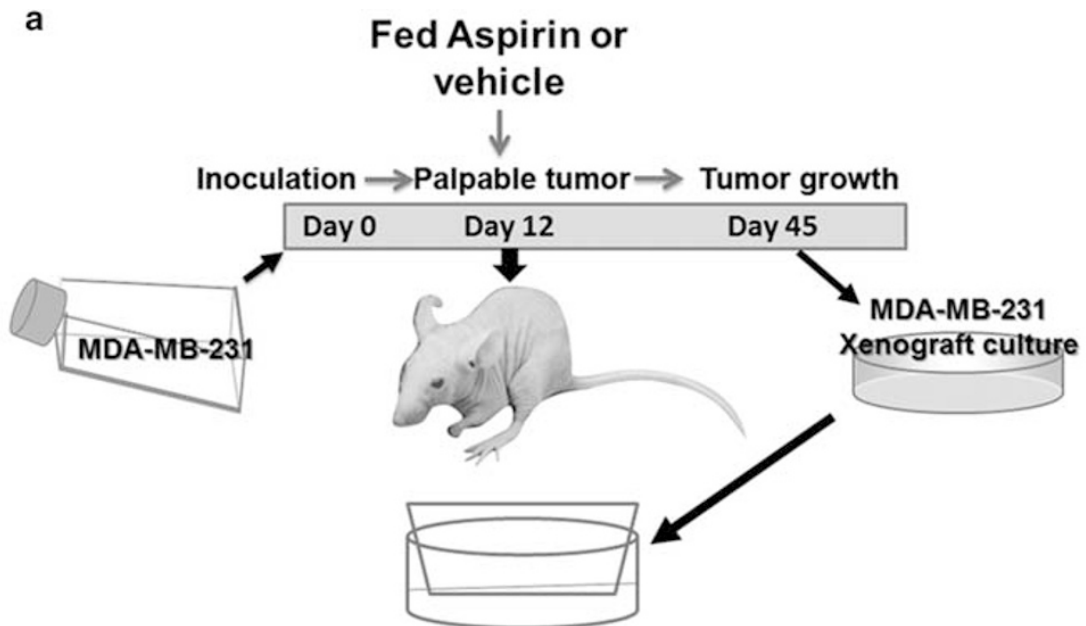

\section{In vitro migration}

b

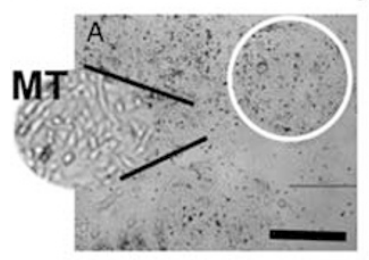

No ASA
Xenograft Culture

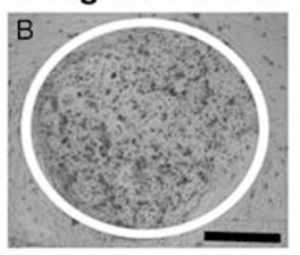

d

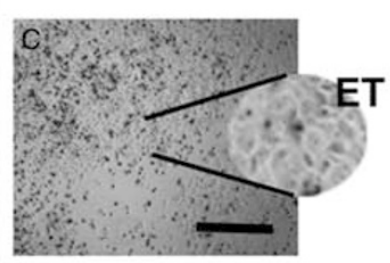

ASA
C

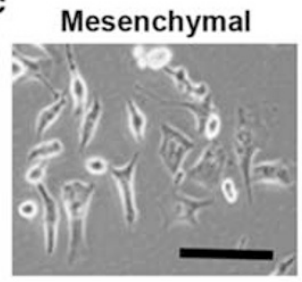

No ASA

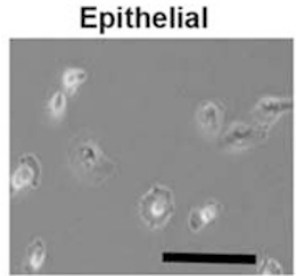

ASA

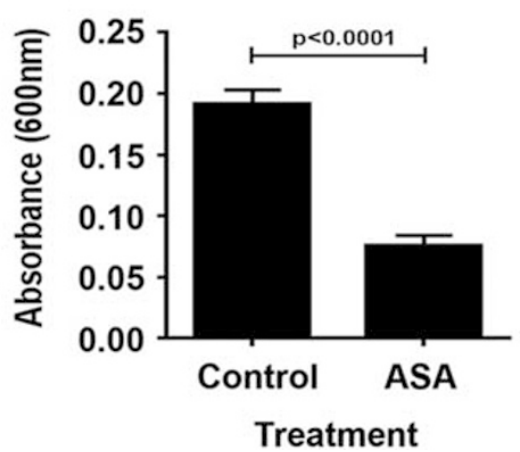

e
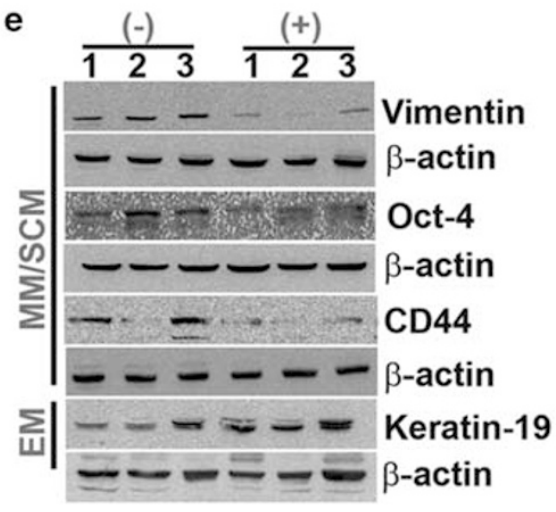

Figure 6 Effects of ASA on morphology and functional behavior of MDA-MB-231 tumor xenograft cells in vitro and in vivo. (a) An experimental scheme is shown to test the ASA effect on reprogramming and migration of MDA-MB-231 tumor xenograft cells. (b) ASA blocks clonal growth of MDA-MB-231 tumor xenograft cells in vitro. Untreated xenograft tumor cells form clonal growth under culture conditions of $(A)$ low magnification $(\times 150)$ and $(B)$ high magnification ( $\times 200)$, whereas no clonal growth was formed by ASA-treated xenograft tumor cells (C). MT, mesenchymal type; ET, epithelial type. Scale bar $=50 \mu \mathrm{m}$. (c) Representative images of morphological alternation from mesenchymal to epithelial transition following ASA treatment. Scale bar $=50 \mu \mathrm{m}$. (d) ASA blocks in vitro migration of MDA-MB-231 tumor xenograft cells. Data show mean \pm s.d. and are representative of at least three independent experiments. (e) Detection of epithelial, mesenchymal, and stem cell markers in ASA-treated and untreated MDA-MB-231 tumor xenograft cells $(n=3)$ by western blotting. $\beta$-Actin was used as the loading control. MM, mesenchymal markers, SCM, stem cell markers; EM, epithelial markers. The quantitative analysis of each protein marker was performed and included as Supplementary Figure S4.

spheres with smaller diameters as compared with controls (Figures $8 \mathrm{a}-\mathrm{c}$ ). The treatment of hrTGF- $\beta$ protein suppresses the ASA effect, and cells regain their sphere-forming ability. The cells treated with hrTGF- $\beta$ alone also showed significant enhancement in sphere-forming ability compared with controls (Figure 8c). Next, we examined the effect of hrTGF- $\beta$ protein on stem cell/mesenchymal protein markers in ASA-preexposed cells. The treatment of hrTGF- $\beta$ protein drastically recovers the expressions of $\mathrm{CD} 44, \mathrm{ALDH}$, and vimentin in ASA-exposed MDA-MB-231 cells where 


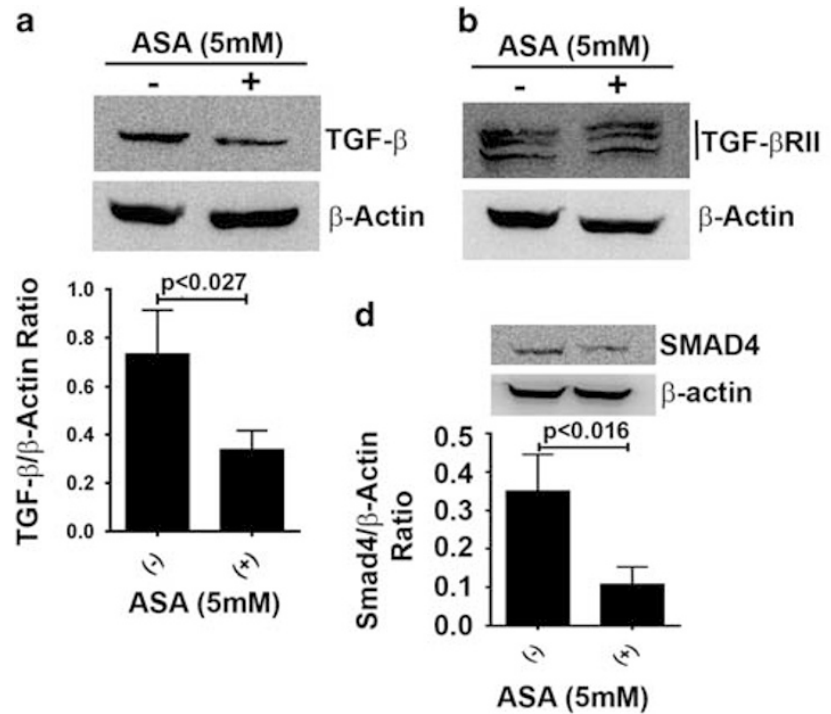

\section{c}

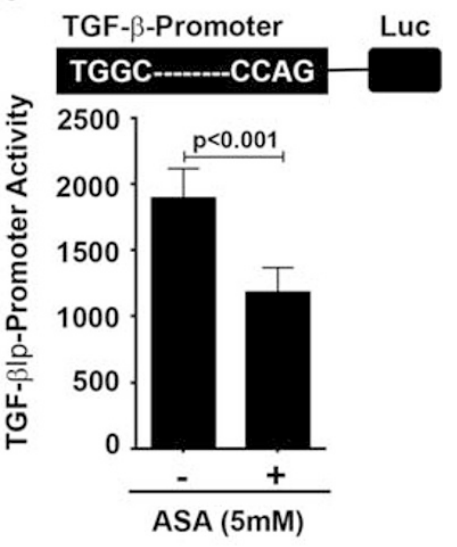

Figure 7 ASA inhibits TGF- $\beta$-SMAD4 signaling in MDA-MB-231 cells. (a) Western blot of TGF- $\beta$ in control and ASA-treated MDA-MB-231 cells. Bar diagram shows the fold changes of TGF- $\beta$-expression after normalization of $\beta$-actin. Data are represented as mean \pm s.d. (b) Effects of ASA on the expression of TGF- $\beta$ RII in MDA-MB-231 cells by western blot. $\beta$-Actin was used as internal control. (c, upper panel) Schematic demonstration of TGF- $\beta$ promoter sequences/LUC plasmid transfected in MDA-MB-231 cells. (c, lower panel) The changes of TGF- $\beta$-promoter activity after ASA treatment in MDA-MB-231 cells by luciferase assay. Error bar indicates s.d. of mean of the triplicate experiments. (d) Western blot profile of SMAD4 protein in control and ASA-treated MDA-MB-231 cells. Histogram shows the fold changes of SMAD4 expression after normalization of $\beta$-actin. Data are represented as mean \pm s.d.

expressions were minimal or undetectable (Figure $8 \mathrm{~d}$ ). Finally, to examine the effect of hrTGF- $\beta$ protein on ASAinduced inhibition of migration of MDA-MB-231 cells, we performed in vitro cell migration assay. The study showed that hrTGF- $\beta$ treatment prevents ASA-induced inhibition of migration of MDA-MB-231 cells (Figure 8e). Collectively, these studies suggest that that reduction in sphere-forming ability and migration of BC cells by ASA is mediated through inhibition of endogenous TGF- $\beta$ signaling. Conversely, we failed to observe any significant role of TGF- $\beta$ on ASAinduced apoptosis (Supplementary Figure S7).

\section{DISCUSSION}

In this study, we demonstrate that ASA not only suppresses ER-positive and TNBC cell growth in vitro and in vivo by inducing apoptotic pathways, but also suppresses the growth of TICs/CSCs that are often considered residual cells, because after conventional therapy, these cells display mesenchymal and tumor-initiating landscapes and relapse. ${ }^{7,8,50}$ The growth-inhibitory effect of ASA is more pronounced in vivo as compared with tissue culture setup with unknown reasons. In addition, ASA reverses EMT to MET through triggering molecular reprogramming switch in BC cells. These entire events could be mediated via regulation of TGF- $\beta$ signaling.

There is an increasing body of evidence indicating a link between ASA intake and a reduction in BC risk in pre- and post-menopausal women. ${ }^{51,52}$ The results of in vitro as well as animal studies also found an association between ASA use and growth inhibition of BC cells. ${ }^{33,53,54}$ Ironically, the results from clinical and preclinical studies are inconsistent, ${ }^{52,55}$ and thus a dilemma emerged about the role of ASA in prevention or delaying $\mathrm{BC}$ growth. Given the importance of this dilemma, we investigated the impact of ASA on different BC cell growth. We show that ASA promotes growth arrest and cell killing (ie, cytostatic and cytotoxic) in different BC cell lines in a dose- and time-dependent manner (Figure 1 and Supplementary Figure S3). The cytostatic and cytotoxic effects were first identified at $1 \mathrm{mM}$ dose of ASA beginning at $72 \mathrm{~h}$. Moreover, the growth-inhibition effect of ASA (75 mg/ $\mathrm{kg}$ body wt/day for 5 days per week) was also detected in MDA-MB-231 tumor xenografts (Figure 2). Importantly, these studies uncover two vital facets of ASA action. These include: (1) ASA is more effective in vivo as compared with tissue culture setup and (2) ASA delays tumor growth efficiently in preexposed mice as compared with postexposed mice. Thus, our study is consistent with recent observations, ${ }^{12,56}$ and we predict that ASA treatment, possibly chronic low dose, may significantly reduce or delay BC growth irrespective of the subtypes (ie, ER positive or TNBC).

Mechanistically, it has been proposed that the anticancer effect of ASA is mediated through COX-dependent ${ }^{36,37,57,58}$ and -independent pathways. ${ }^{53,54,59}$ Recent studies have shown that MCF-7 mammospheres are insensitive to the cyclooxygenase pathway, and the COX-2 inhibitor (Indomethacin) was unable to reduce the mammosphere-forming capacity of MDA-MB-231 cells. However, these studies also showed that prostaglandin E receptor, which is a downstream regulator of COX-2 enzyme, plays critical role in regulation of stemness of BC cells. ${ }^{60,61}$ We found that ASA was unable to regulate COX-2 expression at the protein levels in 


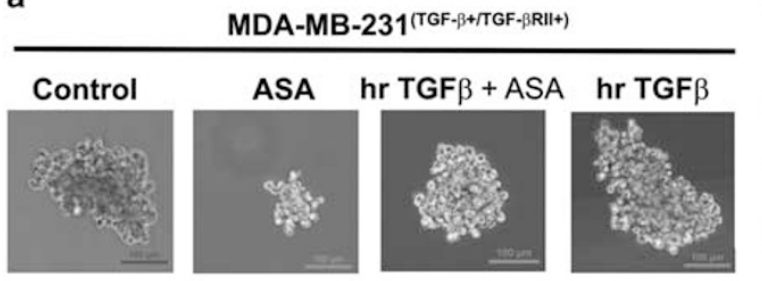

b

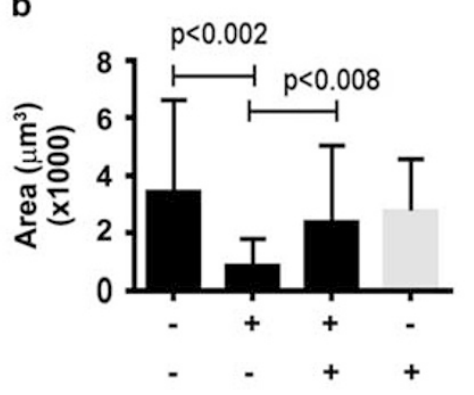

C

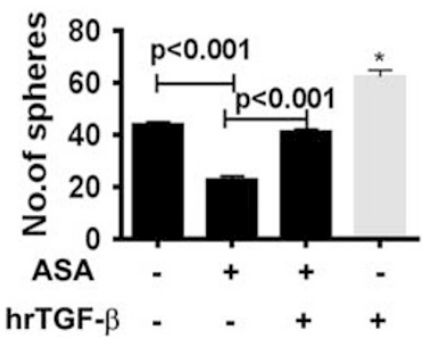

d

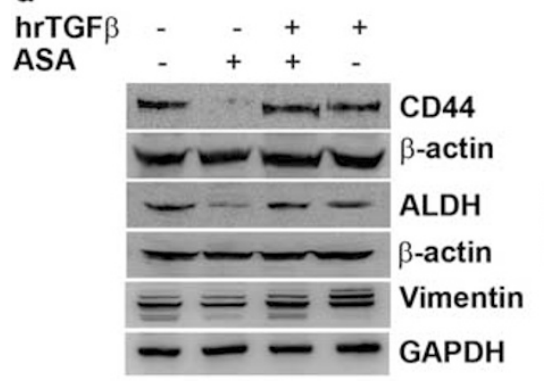

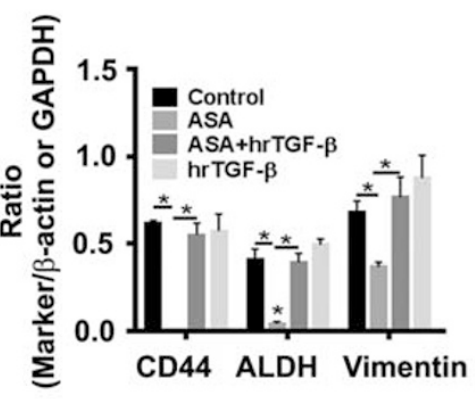

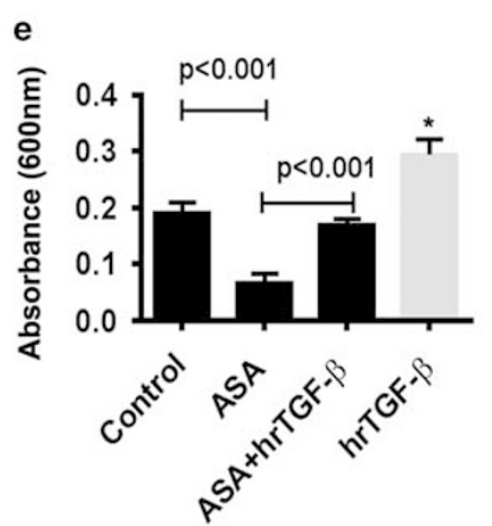

Figure 8 Effect of hrTGF- $\beta$ ligand on sphere-forming ability/self-renewal capacity and migration of MDA-MB-231 cells. (a) Representative images of mammospheres treated as indicated in the figure. Scale bar $=50 \mu \mathrm{m}$. (b) The data are presented as the area of mammospheres. Error bars represent mean \pm s.d. of five separate experiments and 10 fields of each experiment. ${ }^{*} P<0.01$ vs controls. (c) The data are presented as the number of mammospheres. Error bars represent mean \pm s.d. of five separate experiments. ${ }^{*} P<0.01$ vs controls. (d) Western blot analysis of epithelial and mesenchymal/stem cell protein markers in MDA-MB-231 cells treated with hrTGF- $\beta(10 \mathrm{ng} / \mathrm{ml})$ for $48 \mathrm{~h}$ in the presence or absence of ASA. $\beta$-Actin or GAPDH was used as loading control. Error bars represent mean \pm s.d. of five separate experiments. ${ }^{*} P<0.001$ vs controls. (e) MDA-MB-231 cells were treated with ASA $(5.0 \mathrm{mM})$ or DMSO for $72 \mathrm{~h}$ in the presence or absence of hrTGF- $\beta(10 \mathrm{ng} / \mathrm{ml})$ followed by overnight migration toward serum using an in vitro modified Boyden chamber assay. Error bars represent mean \pm s.d. of five separate experiments. ${ }^{*} P<0.01$ vs controls.

MDA-MB-231 BC cells (Supplementary Figure S3). Therefore, from these collective studies, we neither strongly support the involvement of COX-2 signaling nor are able to exclude that the COX-2 protein might not play any role in the growth of $\mathrm{BC}$ cells or breast tumor-initiating cells or both. Further studies are warranted that are in progress in our laboratory. However, the present studies indicate that ASA induces Caspase-3-derived apoptotic death in BC cells (Figures 1 and 2). Based on these studies we can suggest that ASA-induced apoptotic cell death could be mediated through affecting mitochondrial functions via COX-2-independent or -dependent pathway. ${ }^{53,62}$

A small subpopulation of BC cells, considered BTICs or $\mathrm{BCSCs},{ }^{7,39}$ may resist chemotherapy, and thus in the long run, these residual cells may reinitiate tumor growth. ${ }^{7,63}$ This subpopulation of BC cells are CD44 positive $\left(\mathrm{CD} 44^{+/+}\right)$with less or no $\mathrm{CD} 24\left(\mathrm{CD} 24^{\mathrm{low} /-}\right)$ and typically express multiple nonepithelial protein markers associated with EMT and stemness. ${ }^{39,64}$ They can propagate to form clonal growth and mammospheres in vitro that are surrogate detection methods for cancer stem cell properties. ${ }^{7,24,65,66}$ Our studies found that ASA significantly reduced clonal growth (Figure 3), blocked self-renewal of BTICs (Figure 4), reprogrammed the mesenchymal to epithelial transition (Figures 5 and 6), and reduced aggressive behavior of residual $\mathrm{BC}$ cells. However, the precise mechanisms of ASA action on regulation of pathobiological behavior of BTICs/BCSCs are still unidentified.

Despite functioning in the role of tumor suppressor, TGF- $\beta$ also strongly manifested that TGF- $\beta$ signaling is responsible for tumor progression through promoting the self-renewal capacity of BCSCs and EMT, the acquisition of an invasive phenotype, and metastatic behavior. ${ }^{44,47}$ The tumorpromoting behavior of TGF- $\beta$ is a complex ${ }^{67,68}$ and still an undefined process. ${ }^{44}$ Previous studies in a frequently used TGF- $\beta$-induced EMT model showed that Smad signaling was critical in TGF- $\beta$-induced EMT and aggressive phenotypes. ${ }^{69,70}$ In addition, a previous study demonstrated that SMAD4 plays a vital role in TGF- $\beta$-mediated breast tumor progression. ${ }^{48}$ Our findings demonstrate that ASA significantly blocks both TGF- $\beta$ and SMAD4 productions in MDA-MB-231 cells parallel with inhibition of self-renewal 
capacity and migration (Figures 5,6,7). The antitumorigenic effects of ASA can be blocked by exogenous addition of hrTGF- $\beta$ ligand (Figure 8). Thus, we can postulate that ASA-induced inhibition of the self-renewal capacity of BTICs/ BCSCs and their migration promotes reprogramming of MET, and it could be mediated through the suppression of the TGF- $\beta /$ SMAD4 signaling pathway (Figure 8). However, the mechanism of action of regulation of TGF- $\beta$-signaling by ASA is still unclear. Recently, it has been postulated that circulating cancer cells can activate platelets to secrete $\alpha$-granules that are rich sources of EMT-inducing growth factors including TGF- $\beta$, and that this can be inhibited by ASA because of COX-1 inhibition. ${ }^{71}$ As COX-1 is abundantly expressed in human breast tissue samples and cell lines, ${ }^{72}$ we can anticipate that COX-1 may play critical role in the regulation of TGF- $\beta$ by ASA. However, more investigations are warranted.

Collectively, our studies elucidate previously unrecognized actions of ASA in controlling the tumor-initiating properties as well as propagation of BC cells. Moreover, these studies shed light on how ASA treatment can orchestrate and reprogram sophisticated regulation in complex BC cell-fate decisions and make them less aggressive so that they die.

Supplementary Information accompanies the paper on the Laboratory Investigation website (http://www.laboratoryinvestigation.org)

\section{ACKNOWLEDGMENTS}

We thank all members of CRU for their help in generating the manuscript, with Kim Frolander editing the manuscript. These works are supported by VA Merit Review grants (to SKB and SB).

\section{DISCLOSURE/CONFLICT OF INTEREST}

The authors declare no conflict of interest.

1. Siegel R, Naishadham D, Jemal A. Cancer statistics, 2012. CA Cancer J Clin 2012;62():10-29.

2. Banerjee SK, Banerjee S. CCN5/WISP-2: a micromanager of breast cancer progression. J Cell Commun Signal 2012;6:63-71.

3. Higgins MJ, Baselga J. Breast cancer in 2010: novel targets and therapies for a personalized approach. Nat Rev Clin Oncol 2011;8: 65-66.

4. Higgins MJ, Baselga J. Targeted therapies for breast cancer. J Clin Invest 2011;121:3797-3803.

5. Lin WC, Rajbhandari N, Wagner KU. Cancer cell dormancy in novel mouse models for reversible pancreatic cancer: a lingering challenge in the development of targeted therapies. Cancer Res 2014;74: 2138-2143.

6. Aguirre-Ghiso JA. Models, mechanisms and clinical evidence for cancer dormancy. Nat Rev Cancer 2007;7:834-846.

7. Creighton $\mathrm{CJ}$, Li $X$, Landis $M$ et al. Residual breast cancers after conventional therapy display mesenchymal as well as tumor-initiating features. Proc Natl Acad Sci USA 2009;106:13820-13825.

8. Balko JM, Cook RS, Vaught DB et al. Profiling of residual breast cancers after neoadjuvant chemotherapy identifies DUSP4 deficiency as a mechanism of drug resistance. Nat Med 2012;18:1052-1059.

9. Burn J, Bishop DT, Chapman PD et al. A randomized placebo-controlled prevention trial of aspirin and/or resistant starch in young people with familial adenomatous polyposis. Cancer Prev Res (Phila) 2011;4: 655-665.

10. Burn J, Gerdes AM, Macrae F et al. Long-term effect of aspirin on cancer risk in carriers of hereditary colorectal cancer: an analysis from the CAPP2 randomised controlled trial. Lancet 2011;378:2081-2087.
11. Chan AT, Arber N, Burn J et al. Aspirin in the chemoprevention of colorectal neoplasia: an overview. Cancer Prev Res (Phila) 2012;5: 164-178.

12. Thorat MA, Cuzick J. Role of aspirin in cancer prevention. Curr Oncol Rep 2013;15:533-540.

13. Jacobs EJ, Newton CC, Gapstur SM et al. Daily aspirin use and cancer mortality in a large US cohort. J Natl Cancer Inst 2012;104:1208-1217.

14. Thun MJ, Jacobs EJ, Patrono C. The role of aspirin in cancer prevention. Nat Rev Clin Oncol 2012;9:259-267.

15. Tan XL, Reid Lombardo KM, Bamlet WR et al. Aspirin, nonsteroidal antiinflammatory drugs, acetaminophen, and pancreatic cancer risk: a clinic-based case-control study. Cancer Prev Res (Phila) 2011;4: 1835-1841.

16. Algra AM, Rothwell PM. Effects of regular aspirin on long-term cancer incidence and metastasis: a systematic comparison of evidence from observational studies versus randomised trials. Lancet Oncol 2012;13: 518-527.

17. Holmes MD, Chen WY, Li $L$ et al. Aspirin intake and survival after breast cancer. J Clin Oncol 2010;28:1467-1472.

18. Kambhampati $S$, Rajewski RA, Tanol $M$ et al. A second-generation 2-methoxyestradiol prodrug is effective against Barrett's adenocarcinoma in a mouse xenograft model. Mol Cancer Ther 2013;12: 255-263.

19. Dhar G, Banerjee S, Dhar K et al. Gain of oncogenic function of p53 mutants induces invasive phenotypes in human breast cancer cells by silencing CCN5/WISP-2. Cancer Res 2008;68:4580-4587.

20. Dhar K, Dhar G, Majumder $M$ et al. Tumor cell-derived PDGF-B potentiates mouse mesenchymal stem cells-pericytes transition and recruitment through an interaction with NRP-1. Mol Cancer 2010;9:209.

21. Haque I, De A, Majumder M et al. The matricellular protein CCN1/Cyr61 is a critical regulator of Sonic Hedgehog in pancreatic carcinogenesis. J Biol Chem 2012;287:38569-38579.

22. Banerjee S, Dhar G, Haque I et al. CCN5/WISP-2 expression in breast adenocarcinoma is associated with less frequent progression of the disease and suppresses the invasive phenotypes of tumor cells. Cancer Res 2008;68:7606-7612.

23. Ying $\mathrm{H}$, Elpek KG, Vinjamoori $A$ et al. PTEN is a major tumor suppressor in pancreatic ductal adenocarcinoma and regulates an NF-kappaBcytokine network. Cancer Discov 2011;1:158-169.

24. Dontu G, Abdallah WM, Foley JM et al. In vitro propagation and transcriptional profiling of human mammary stem/progenitor cells. Genes Dev 2003;17:1253-1270.

25. Cordenonsi M, Zanconato F, Azzolin L et al. The Hippo transducer TAZ confers cancer stem cell-related traits on breast cancer cells. Cell 2011;147:759-772.

26. Ikushima $\mathrm{H}$, Todo $\mathrm{T}$, Ino $\mathrm{Y}$ et al. Autocrine TGF-beta signaling maintains tumorigenicity of glioma-initiating cells through Sry-related HMG-box factors. Cell Stem Cell 2009;5:504-514.

27. Haque I, Banerjee $S$, Mehta $S$ et al. Cysteine-rich 61-connective tissue growth factor-nephroblastoma-overexpressed 5 (CCN5)/Wnt-1induced signaling protein-2 (WISP-2) regulates microRNA-10b via hypoxia-inducible factor-1alpha-TWIST signaling networks in human breast cancer cells. J Biol Chem 2011;286:43475-43485.

28. Reagan-Shaw $S$, Nihal M, Ahmad N. Dose translation from animal to human studies revisited. FASEB J 2008;22:659-661.

29. Frantz B, O'Neill EA. The effect of sodium salicylate and aspirin on NF-kappa B. Science 1995;270:2017-2019.

30. Rainsford KD. Aspinin and the Salicylates. Butterworths: Boston, MA, 1984.

31. Borthwick GM, Johnson AS, Partington $M$ et al. Therapeutic levels of aspirin and salicylate directly inhibit a model of angiogenesis through a Cox-independent mechanism. FASEB J 2006;20: 2009-2016.

32. Yin MJ, Yamamoto $Y$, Gaynor RB. The anti-inflammatory agents aspirin and salicylate inhibit the activity of I(kappa)B kinase-beta. Nature 1998;396:77-80.

33. Choi BH, Chakraborty G, Baek $\mathrm{K}$ et al. Aspirin-induced $\mathrm{BCl}-2$ translocation and its phosphorylation in the nucleus trigger apoptosis in breast cancer cells. Exp Mol Med 2013;45:e47.

34. Pathi S, Jutooru I, Chadalapaka G et al. Aspirin inhibits colon cancer cell and tumor growth and downregulates specificity protein (Sp) transcription factors. PLoS One 2012;7:e48208. 
35. Din FV, Dunlop MG, Stark LA. Evidence for colorectal cancer cell specificity of aspirin effects on NF kappa B signalling and apoptosis. $\mathrm{Br}$ J Cancer 2004:91:381-388.

36. Lin HY, Delmas D, Vang $\mathrm{O}$ et al. Mechanisms of ceramide-induced COX-2-dependent apoptosis in human ovarian cancer OVCAR-3 cells partially overlapped with resveratrol. J Cell Biochem 2013;114: 1940-1954.

37. $\mathrm{Xu} \mathrm{L}$, Stevens J, Hilton MB et al. COX-2 inhibition potentiates antiangiogenic cancer therapy and prevents metastasis in preclinical models. Sci Transl Med 2014;6:242ra284.

38. Nzeako UC, Guicciardi ME, Yoon JH et al. COX-2 inhibits Fas-mediated apoptosis in cholangiocarcinoma cells. Hepatology 2002;35:552-559.

39. Al-Hajj M, Wicha MS, Benito-Hernandez A et al. Prospective identification of tumorigenic breast cancer cells. Proc Natl Acad Sci USA 2003;100:3983-3988

40. Rangarajan A, Weinberg RA. Opinion: Comparative biology of mouse versus human cells: modelling human cancer in mice. Nat Rev Cancer 2003;3:952-959.

41. Manuel Iglesias J, Beloqui I, Garcia-Garcia F et al. Mammosphere formation in breast carcinoma cell lines depends upon expression of E-cadherin. PLoS One 2013;8:e77281.

42. Chaffer $\mathrm{CL}$, Weinberg RA. A perspective on cancer cell metastasis. Science 2011:331:1559-1564.

43. Larue L, Bellacosa A. Epithelial-mesenchymal transition in development and cancer: role of phosphatidylinositol 3' kinase/AKT pathways. Oncogene 2005;24:7443-7454.

44. Derynck R, Akhurst RJ, Balmain A. TGF-beta signaling in tumor suppression and cancer progression. Nat Genet 2001;29:117-129.

45. Schniewind B, Groth S, Sebens Muerkoster S et al. Dissecting the role of TGF-beta type I receptor/ALK5 in pancreatic ductal adenocarcinoma: Smad activation is crucial for both the tumor suppressive and prometastatic function. Oncogene 2007;26:4850-4862.

46. Barcellos-Hoff $\mathrm{MH}$, Akhurst RJ. Transforming growth factor-beta in breast cancer: too much, too late. Breast Cancer Res 2009;11:202.

47. Penuelas S, Anido J, Prieto-Sanchez RM et al. TGF-beta increases glioma-initiating cell self-renewal through the induction of LIF in human glioblastoma. Cancer Cell 2009;15:315-327.

48. Deckers M, van Dinther M, Buijs J et al. The tumor suppressor Smad4 is required for transforming growth factor beta-induced epithelial to mesenchymal transition and bone metastasis of breast cancer cells. Cancer Res 2006;66:2202-2209.

49. Byon $\mathrm{CH}_{\text {, Hardy } \mathrm{RW}}$, Ren $\mathrm{C}$ et al. Free fatty acids enhance breast cancer cell migration through plasminogen activator inhibitor-1 and SMAD4. Lab Invest 2009;89:1221-1228.

50. Franci C, Zhou J, Jiang Z et al. Biomarkers of residual disease, disseminated tumor cells, and metastases in the MMTV-PyMT breast cancer model. PLoS One 2013;8:e58183.

51. Tait CR. Aspirin and breast cancer prevention-a link to ER status. Breast Cancer Res 2004;6:211-212.

52. Luo $\mathrm{T}$, Yan HM, He $\mathrm{P}$ et al. Aspirin use and breast cancer risk: a metaanalysis. Breast Cancer Res Treat 2012;131:581-587.

53. Alfonso L, Ai G, Spitale RC et al. Molecular targets of aspirin and cancer prevention. Br J Cancer 2014;11:61-67.

54. Lu M, Strohecker A, Chen F et al. Aspirin sensitizes cancer cells to TRAIL-induced apoptosis by reducing survivin levels. Clin Cancer Res 2008;14:3168-3176.
55. Zhang X, Smith-Warner SA, Collins LC et al. Use of aspirin, other nonsteroidal anti-inflammatory drugs, and acetaminophen and postmenopausal breast cancer incidence. J Clin Oncol 2012;30:3468-3477.

56. Chan A. The role of aspirin in colorectal cancer prevention and treatment Oncology (Williston Park) 2013:27:1012, 1014, 1042.

57. Lin HY, Sun M, Tang HY et al. Resveratrol causes COX-2- and p53dependent apoptosis in head and neck squamous cell cancer cells. J Cell Biochem 2008;104:2131-2142.

58. Moon CM, Kwon JH, Kim JS et al. Nonsteroidal anti-inflammatory drugs suppress cancer stem cells via inhibiting PTGS2 (cyclooxygenase 2) and NOTCH/HES1 and activating PPARG in colorectal cancer. Int J Cancer 2014;134:519-529.

59. Dikshit $\mathrm{P}$, Chatterjee $M$, Goswami $A$ et al. Aspirin induces apoptosis through the inhibition of proteasome function. J Biol Chem 2006;281: 29228-29235.

60. Kundu N, Ma X, Kochel T et al. Prostaglandin E receptor EP4 is a therapeutic target in breast cancer cells with stem-like properties. Breast Cancer Res Treat 2014;143:19-31.

61. Majumder M, Xin X, Liu L et al. Prostaglandin E2 receptor EP4 as the common target on cancer cells and macrophages to abolish angiogenesis, lymphangiogenesis, metastasis, and stem-like cell functions. Cancer Sci 2014;105:1142-1151.

62. Wolf $\mathrm{BB}$, Schuler $\mathrm{M}$, Echeverri $\mathrm{F}$ et al. Caspase- 3 is the primary activator of apoptotic DNA fragmentation via DNA fragmentation factor-45/ inhibitor of caspase-activated DNase inactivation. J Biol Chem 1999;274:30651-30656.

63. Jones RJ, Matsui WH, Smith BD. Cancer stem cells: are we missing the target? J Natl Cancer Inst 2004;96:583-585.

64. Trimboli AJ, Fukino K, de Bruin A et al. Direct evidence for epithelialmesenchymal transitions in breast cancer. Cancer Res 2008;68:937-945.

65. Li X, Lewis MT, Huang J et al. Intrinsic resistance of tumorigenic breast cancer cells to chemotherapy. J Natl Cancer Inst 2008;100: 672-679.

66. Gou S, Liu T, Wang $C$ et al. Establishment of clonal colony-forming assay for propagation of pancreatic cancer cells with stem cell properties. Pancreas 2007;34:429-435.

67. Oft M, Akhurst RJ, Balmain A. Metastasis is driven by sequential elevation of $\mathrm{H}$-ras and Smad2 levels. Nat Cell Biol 2002:4:487-494.

68. Lehmann K, Janda E, Pierreux CE et al. Raf induces TGFbeta production while blocking its apoptotic but not invasive responses: a mechanism leading to increased malignancy in epithelial cells. Genes Dev 2000;14: 2610-2622.

69. Piek E, Moustakas A, Kurisaki A et al. TGF-(beta) type I receptor/ALK-5 and Smad proteins mediate epithelial to mesenchymal transdifferentiation in NMuMG breast epithelial cells. J Cell Sci 1999:112:4557-4568.

70. Valcourt U, Kowanetz $\mathrm{M}, \mathrm{Niimi} H$ et al. TGF-beta and the Smad signaling pathway support transcriptomic reprogramming during epithelial-mesenchymal cell transition. Mol Biol Cell 2005;16: 1987-2002.

71. Lou XL, Deng J, Deng H et al. Aspirin inhibit platelet-induced epithelialto-mesenchymal transition of circulating tumor cells (Review). Biomed Rep 2014;2:331-334.

72. Hwang D, Scollard D, Byrne J et al. Expression of cyclooxygenase-1 and cyclooxygenase-2 in human breast cancer. J Natl Cancer Inst 1998;90: 455-460. 